\title{
New Approach Based on Fuzzy Hypergraphs in Granular Computing (An Application to the Urban Vulnerability Assessment)
}

Abdolreza Zarandi Baghini

Islamic Azad University Kerman Branch

Hojjat Babaei

Islamic Azad University Kerman Branch

Ramin Tabatabaei Mirhosseini ( $\nabla$ tabatabaei@iauk.ac.ir)

Islamic Azad University Kerman Branch https://orcid.org/0000-0001-8292-8571

Research article

Keywords: Hypergraph, Fuzzy membership degree, Fuzzy hypergraph, Classification, Granular computing, Urban vulnerability

Posted Date: February 17th, 2022

DOI: https://doi.org/10.21203/rs.3.rs-1167172/v1

License: (a) (1) This work is licensed under a Creative Commons Attribution 4.0 International License. Read Full License 


\section{New approach based on fuzzy hypergraphs in granular computing} (an application to the urban vulnerability assessment)

(

(1)

(1)
Abdolreza Zarandi Baghini ${ }^{1 \mathrm{a}}{ }_{\text {,Hojjat } \text { Babaei }^{1 \mathrm{~b}} \text { and Ramin Tabatabaei Mirhosseini*2 }}{ }^{2}$

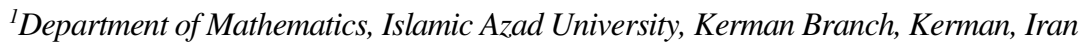

${ }^{2}$ Department of Civil Engineering, Islamic Azad University, Kerman Branch, Kerman, Iran

\begin{abstract}
Classifying objects based on the simultaneous impact of various parameters has always been challenging due to heterogeneity, impact conflict, and sometimes parameter uncertainty. The purpose of this study is to provide a method for classifying such data. In the proposed method, fuzzy hypergraphs were used to define the granular structures in order to apply the simultaneous effect of heterogeneous and weighted parameters in the classification. This method has been implemented and validated on Fisher intuitive research in relation to the classification of iris flowers. Evaluation and comparison of the proposed method with Fisher's experimental and results showed higher efficiency and accuracy in flower classification. The proposed method has been used to assess the seismic risk of 50,000 buildings based on 10 heterogeneous parameters. Seismic risk classification showed that more than $88 \%$ of buildings were classified, and $12 \%$ of buildings that could not be classified due to excessive scatter of parameter values were classified using a very small confidence radius. The results indicate the ability of the proposed method to classify objects with the least similarity and number of effective parameters in classification.
\end{abstract}

${ }^{*}$ Corresponding author, Associate Professor, E-mail: tabatabaei@iauk.ac.ir

${ }^{a}$ Ph.D. Student, E-mail: zarandi @iauk.ac.ir

b Assistant Professor, E-mail: babaei@iauk.ac.ir 
21 Keyword: Hypergraph, Fuzzy membership degree, Fuzzy hypergraph, Classification, Granular

22 computing, Urban vulnerability.

\section{1. Introduction}

25 One of the main elements for effective response, before natural disasters, is the assessment of 26 urban vulnerability. Urban vulnerability assessment requires access to information and advanced

27 methods of information analysis.

28 Past experiences have shown that earthquakes, as a complex natural phenomenon, are not 29 predictable. However, their effects can be measured by different mathematical patterns and 30 techniques. Many parameters contribute to the damage caused by an earthquake.

31 Parameters which, in addition to uncertainties, are also conflicting in estimating the damage. The 32 multiplicity of parameters, uncertainty and conflict and the placement of the urban zone faces 33 many challenges in a risk class. Finally, seismic risk assessment is affected by the challenges of 34 classification. So far, different approaches have been proposed to assess the urban vulnerability by 35 focusing on the control of uncertainties and opposite conditions of the parameters.

36 In spite of the development of a vulnerability structure based on the GIS software, the obtained 37 results are not above an average estimate of physical and life-threatening losses. This limitation 38 implies discarding the sensitivity of infrastructure systems. The lack of attention to infrastructure 39 systems leads to a reduction in reliability and cascading failure(1). Most of the conventional 40 methods of determining vulnerability risk are merely a specific allocation of risk-taking (241 4).Some studies describe seismic risk using the weight scoring method and cumulative 42 measurement (total weight) of individual events in each criterion $(5,6)$. 
43 A method called Diagram Index (DI) is proposed to determine the interdependence between

44 several properties, based on graph theory. In the DI index, the performance estimation of the

45 fundamental infrastructure of urban systems is investigated, starting with physical damage and

46 then the effects that each node has on the performance of other nodes(1).

47 Previous research has shown that in principle the resonance descriptors are exacerbating the

48 physical hazards. This increases concerns about social, economic and non-flexibility, or lack of 49 ability to deal with physical hazards(7-9).

50 In some methods, by identifying the different structures, the vulnerability of buildings is defined

51 on the basis of being in an urban area. Then the relationship between intensity and damage is

52 obtained by means of the harm matrix $(10,11)$. The vulnerability functions and correlation

53 coefficients can also be used according to expected seismic input intensity(12-14).

54 Recently, a model of vulnerability information systems is proposed as "Common Relevant 55 Operational Picture" (CROP). In order to minimize the risk of relief in the crop model, the 56 possibility of coordination between regions is enabled by allocating small subset of a common 57 database for each area(15).

58 Granular Computing ( $\mathrm{GrC})$ is a novel computational paradigm for processing complex information 59 entities called "Information Granules", which is used to explore hidden, useful and unknown 60 communication in the dataset(16,17).

61 In general, the data granules are a set of entities that are usually placed in a numeric level due to 62 the similarity, functional closeness, consistency or similar cases, as a whole unit(18). In addition 63 to being able to be an independent seed, granules can be a member of another granules. Then we 64 will have a family of the granules, which are considered as a whole. The granules on one level, 65 though they may be relatively independent, are somehow connected to each other in a certain 
66 degree and generally exhibit a particular structure, which is the inner structure of granules. At

67 present, granules are more than a coherent set of methods or principles and an approach for data

68 analysis at different levels in order to detect data, is recommend.

69 As mentioned above, granule computing is not a process or algorithm. There is no specific method 70 which is called "Granule Computing". Granule Computing is used to study the data, which 71 recognizes how different laws in the data can appear at different levels of granularity. With the 72 development of granules, different models of granular computing are proposed and investigated. 73 Among the models are fuzzy sets, rugged sets, and outer space as the main computational 74 models(19).

75 For example, a granular computing-based model is presented based on data tables, and in this 76 model, different methods for construction, interpretation and representation of the granules were 77 investigated(20). Also, some other concepts of granular computing are presented based on fuzzy $78 \operatorname{set}(21)$.

79 Over the past half century, graph theory as a classical mathematical tool, has been applied to many 80 applications in different fields such as economics, computer science, geometry, number theory, 81 optimization, topology and transportation. The graph theory is currently used in granular 82 computing and the representation of seed structures for computer problems research. For example, 83 the adjacency matrix of a simple undirected graph (constrained) is interpreted as a Boolean 84 information table(22).

85 In graph theory, however, some characteristics of the case study may have some sort of uncertainty.

86 For example, in the earthquake and seismic vulnerability assessment, the effect and distance of 87 buildings from blast centers (gas stations and gas pumps) are not precise. In such cases, fuzzy sets 88 and fuzzy logic are used to deal with uncertainty management. 
89 To solve new combinatorial problems, it was necessary to develop the concept of graph theory. In 90 1960, hypergraph theory was introduced as a generalization of graphs, and one of its primary 91 objectives was to generalize some classical results of graph theory(23).

92 The hypergraph theory offers a more powerful tool to analyze and solve real-world problems in 93 the modeling of complex systems. Graphs have the ability to communicate with a maximum of 94 two nodes. It is virtually impossible to use graphs for analysis and discussion of more than two node. One of the motivations for introducing hypergraph is for solving this type of graph problems.

96 Hence, the hypergraph can analyze the connection between members of the finite set and even the 97 infinite nodes. Unlike ordinary graphs, each edge in the hypergraph can consist of an arbitrary number of vertices and each edge in this hypergraph is called hyperedge. In the hypergraph, the 99 vertices can be described in a n-ary relation.

100 Some researchers developed a hypergraph segmentation algorithm based on multi-level patterns, 101 in which a sequence of successive hypergraphs are constructed(24). It shows that a simple granule 102 of the universe can be characterized by a fuzzy equivalence relation or a given partition.

103 For the first time, Zadeh, introduced a special type of subset $\mathrm{X}$ and named it a fuzzy subset, by 104 grading the inaccurate degree of belonging of the members of a subset of the reference set X (25). 105 By combining the benefits of the two fuzzy concepts and hypergraph, fuzzy hypergraph is 106 presented as a modeling structure with fuzzy relation and multiple relationships between 107 objects(26).

108 Previous studies have shown that fuzzy graphs are expressed on the basis of fuzzy relations $(27,28)$.

109 In the studies, some operations have been defined over fuzzy graphs(29,30). Fuzzy graph theory 110 has many applications in various fields, including computer networks, data mining, clustering, 111 differentiation, and recording. Analog fuzzy logic has been discussed in many of the theoretical 
112 concepts of graph theory and in the case of fuzzy graphs is particularly interesting for 113 researchers $(31,32)$. There are also other definitions such as the supplement of fuzzy graph and the 114 characteristics of fuzzy trees $(33,34)$. Recently, the concept of M-fuzzy based graphs and some of 115 its properties have been proposed(35).

116 Finally, an interesting concept called fuzzy hypergraph based on the original idea was generalized 117 and redefined by Kaufman(36). In addition, the concept of fuzzy hypergraphs has been considered 118 and the concept of interval values of fuzzy hypergraphs has been introduced(37,38). In recent 119 years, the concept of intuitive fuzzy hypergraphs as well as bipolar fuzzy hypergraphs and some 120 of their basic features have been expressed $(39,40)$.

121 Classification is easily applicable when faced with a small set of attributes. For example, in a 122 collection of white, black, red and beige cars, we can easily put them in 4 classes. But if the same 123 set includes other features such as year of manufacture, manufacturer, engine size, price, etc., 124 classification becomes a bit complicated. Now suppose you want to classify in a collection of 125 thousands of records and hundreds of unordered attributes with conflicting effects. How can 126 classes and classifying a collection of elements be defined?

127 Increasing the accuracy and focus on some features for classification reduces the accuracy in 128 influencing other features in defining classes and identifying the appropriate class.

129 Considering the hierarchical effect of weighted and heterogeneous parameters in the classification 130 of elements, always reduces the classification accuracy. Highlighting the role of high-level 131 parameters and diminishing the effect of parameters in the lower layers are the main challenges of 132 classifying elements with equal and heterogeneous properties. In this paper, to increase the 133 accuracy in seismic vulnerability assessment and the possibility of better and more accurate 134 decision-making at boundary points, the concepts of fuzzy and granule hypergraphs have been 
135 136

137

used. To define urban seismic risk classes with flexible and floating boundaries and limits, a granular structure based on fuzzy hypergraph has been used. In this method, much more granules are shown. Previous research has been done to investigate how granules are made in different fields, using hypergraphs(41,42).By examining and evaluating each building in the mentioned granular structure, the risk level of the building is calculated and determined. This approach makes it possible to make better decisions at the border points of the classes. In this process, in addition to considering the simultaneous effect of all effective parameters in the classification, the degree of interaction of the parameters with each other is also considered. For verification, the proposed method was implemented in the classification of iris flowers. Fisher has intuitively classified irises(43). The conformity of the classification with Fisher's experimental and intuitive methods indicates the efficiency of the presented research method. This method is then used to assess seismic risk.

\section{General}

In this section, the concepts of granules, granule computing, fuzzy, hypergraph and fuzzy hypergraph are defined.

\subsection{Granule, Granule Computing}

Granular computing is a well-known method in computation and applied mathematics for data processing. Information is divided into granules through the granulation process(20).

Information granule is a set of entities that are obtained from the numerical analysis of the properties of the entity (data) and then it is classified at a certain level based on similarity, functional proximity, physical proximity, or indistinguishability. 
158 Granular data is the lowest level of data that is targeted into a set. This refers to the degree of detail 159 and the size of the class to which the data is divided. For example, dividing people's names into 160 either a single field, consisting of both names and surnames together, or separate fields. The more 161 segmented and specific the data, the more granularity is considered.

162 Putting the data at its proper level depends on the level of knowledge and awareness of the impact 163 of data details on granulation.

164 Classes are described according to whether the grains are large or detailed. The structure of these 165 levels of granulation is determined by the laws of nature or human cognition.

\subsection{Fuzzy Sets}

The key to understanding the difference between a fuzzy set and a classic set is the concept of

169 fuzzy membership degree. In classical logic, the concepts of belonging or non-belonging of a 170 member to a set, are quite definite and precise. So, an object is or is not a member of a set and 171 hence the membership function can only have two values, 0 and 1. In 1965, Lotfi A. Zadeh, 172 introduced a special type of subset $X$ and called it a fuzzy subset by grading the inaccurate degree 173 of belonging members of a subset from a reference set $\mathrm{X}(44)$.

174 Definition 2.1 A "fuzzy subset A" of reference set $X$ or a "fuzzy set A" in reference set X, 175 characterized with membership function $\mu_{\mathrm{A}}: \mathrm{X} \rightarrow[0,1]$ and the membership of each member is 176 graded. The meaning of $\mu_{\mathrm{A}}(x) \in[0,1]$ degree of membership $x \in \mathrm{X}$ in "fuzzy subset A" or "fuzzy 177 set $\mathrm{A} "(44)$.

178 The set $\operatorname{supp} \mu_{\mathrm{A}}=\left\{x \in X \mid \mu_{\mathrm{A}}(x)>0\right\}$ is called the support $\mu_{\mathrm{A}}$, and $\mathrm{h}\left(\mu_{\mathrm{A}}\right)$ is the height display $\mu$ 179 such that $\mathrm{h}\left(\mu_{\mathrm{A}}\right)=\max \left\{\mu_{\mathrm{A}}(x) \mid x \in \mathrm{X}\right\}$. 
180 If $u$ and $v$ are fuzzy sets, then $u \wedge v=\min \{u, v\}$ and $u \vee v=\max \{u, v\}$. We write $u \leq v$

181 if $u(x) \leq v(x)$ for all $x \in \mathrm{X}$ also $u<v$ if $u \leq v$ and $u(x)<v(x)$ for some $x \in \mathrm{X}$.

183 2.3. Hypergraph and fuzzy hypergraph

184 In 1960, the theory of hypergraphs was introduced as a generalization of graphs. Unlike normal 185 graphs, each edge in a hypergraph can contain an arbitrary number of vertices [23].

186 Definition 2.2 The pair $\mathrm{H}=(\mathrm{X}, \mathbf{E})$ is called a hypergraph on a finite set $\mathrm{X}$ if $\mathrm{E}$ is a finite family of 187 non-empty subsets $\mathrm{X}$ such that:

191 Sometimes a set of vertices is represented by $\mathrm{X}(\mathrm{H})$ and the edge set by $\mathrm{E}(\mathrm{H})(45)$.

192 A hypergraph is called a simple hypergraph if $\mathrm{E}$ does not contain duplicate edges and $193 \forall \mathrm{A}, \mathrm{B} \in \mathrm{E}, \mathrm{A} \subset \mathrm{B}$ then $\mathrm{A}=\mathrm{B}$.

194 Example 2.1 Suppose $X=\{1,2,3,4,5,6,7,8,9,10\}$ and $E=\left\{E_{1}, E_{2}, E_{3}, E_{4}\right\}$ such that $E_{1}=\{1,3,8,10\}$

$195 \quad, \mathrm{E}_{2}=\{1,4,5\}, \mathrm{E}_{3}=\{6,5,8,9\}, \mathrm{E}_{4}=\{2,7,8\}$.

196 By definition $2.2 \mathrm{H}=(\mathrm{X}, \mathrm{E})$ is a hypergraph on the set $\mathrm{X}$. Each of the subsets $\mathrm{E}_{1}, \mathrm{E}_{2}, \mathrm{E}_{3}, \mathrm{E}_{4}$ edges and 197 their members are the vertices of the hypergraph. 


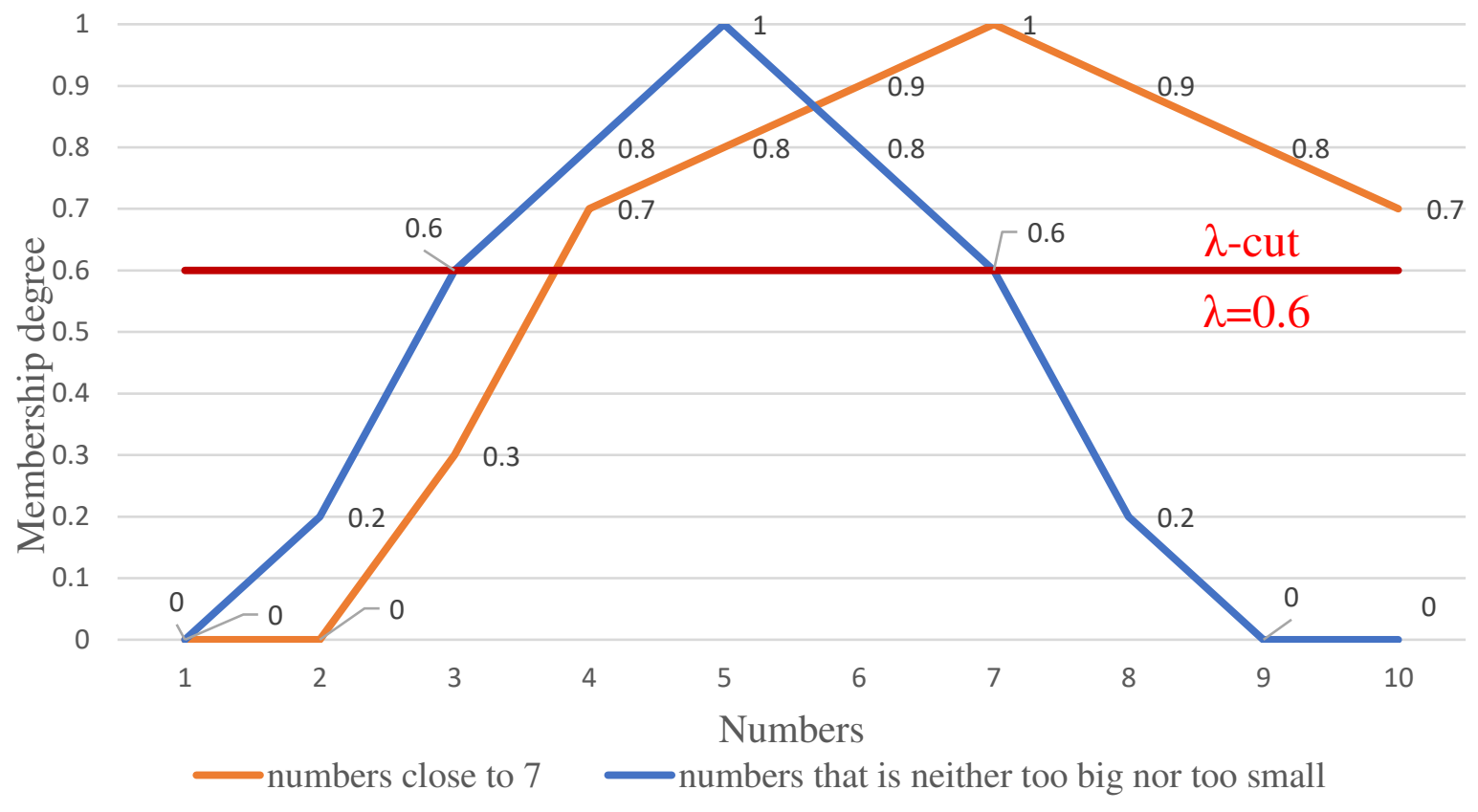

Figure (1): Diagram of two fuzzy relations defined on the $\mathrm{X}$ set

Definition 2.3 Let $\mathrm{X}$ is a finite set and $\varepsilon$ a finite family of nontrivial fuzzy subsets on the set $\mathrm{X}$ such that $\mathrm{X}=\mathrm{U}\{\operatorname{supp} \mu \mid \mu \in \varepsilon\}$, then the pair $\mathrm{H}=(\mathrm{X}, \varepsilon)$ is a fuzzy hypergraph on the set $\mathrm{X}$, and $\mathrm{X}$ the set of vertices and $\varepsilon$ is called the set of fuzzy edges (the family of edges fuzzy) of $H(37)$.

Definition 2.4 A fuzzy hypergraph $\mathrm{H}=(\mathrm{X}, \varepsilon)$ is called simple if $\varepsilon$ does not contain duplicate fuzzy edges and whenever $u, v \in \varepsilon, u \leq v$ then $u=v(37)$.

Definition 2.5 Suppose $\mathrm{H}=(\mathrm{X}, \varepsilon)$ is a fuzzy hypergraph and $\mu \in \varepsilon$ and $0 \leq \lambda \leq 1$. $\lambda$-cut of $\mu$ is defined

207 as follows $\mu_{\lambda}=\{x \in \mathrm{X} \mid \mu(\mathrm{x}) \geq \lambda\}$ (37).

208 Also, assuming that $\mathrm{E}_{\lambda}=\left\{\mu_{\lambda} \mid \mu \in \varepsilon\right\}$ and $\mathrm{X}_{\lambda}=\mathrm{U}\left\{\mu_{\lambda} \mid \mu \in \varepsilon\right\}$. If $\mathrm{E}_{\lambda} \neq \varnothing$ then the hypergraph 209 $\mathrm{H}_{\lambda}=\left(\mathrm{X}_{\lambda}, \mathrm{E}_{\lambda}\right)$ is called a $\lambda$-level hypergraph of $\mathrm{H}$. 
210 Example 2.2 By defining a fuzzy relation, we define a fuzzy hypergraph on $\mathrm{X}$ set.

$211 \cdot$ Relation $\mu_{\mathrm{A}}$ a set of numbers close to 7

$$
\mu_{\mathrm{A}}(x)= \begin{cases}0 & \text { where } x=1 \\ 0 & \text { where } x=2 \\ 0.3 & \text { where } x=3 \\ 0.7 & \text { where } x=4 \\ 0.8 & \text { where } x=5 \\ 0.9 & \text { where } x=6 \\ 1 & \text { where } x=7 \\ 0.9 & \text { where } x=8 \\ 0.8 & \text { where } x=9 \\ 0.7 & \text { where } x=10\end{cases}
$$

$$
\mu_{\mathrm{A}}: \mathrm{X} \rightarrow[0,1]
$$$$
\mathrm{A}=\{(1,0),(2,0),(3,0.3),(4,0.7),(5,0.8),(6,0.9),(7,1),(8,0.9),(9,0.8),(10,0.7)\}
$$

$\operatorname{supp} \mu_{\mathrm{A}}=\{3,4,5,6,7,8,9,10\}$

let $\lambda=0.6$ so $\mu_{\mathrm{A}_{0.6}}=\{4,5,6,7,8,9,10\}$

212 - Relation $\mu_{\mathrm{B}}$ a set of numbers that is neither too big nor too small.

$$
\mu_{\mathrm{B}}(x)= \begin{cases}0 & \text { where } x=1 \\ 0.2 & \text { where } x=2 \\ 0.6 & \text { where } x=3 \\ 0.8 & \text { where } x=4 \\ 1 & \text { where } x=5 \\ 0.8 & \text { where } x=6 \\ 0.6 & \text { where } x=7 \\ 0.2 & \text { where } x=8 \\ 0 & \text { where } x=9 \\ 0 & \text { where } x=10\end{cases}
$$

$$
\operatorname{supp} \mu_{\mathrm{B}}=\{2,3,4,5,6,7,8,9\}
$$

let $\lambda=0.6$ so $\mu_{\mathrm{B}_{0.6}}=\{4,5,6,7\}$ 
213 If $\varepsilon=\left\{\mu_{\mathrm{A}}, \mu_{\mathrm{B}}\right\}$ then $\mathrm{X} \neq \operatorname{supp} \mu_{\mathrm{A}} \mathrm{U} \operatorname{supp} \mu_{\mathrm{B}}=\{2,3,4,5,6,7,8,9,10\}$, by Definition 2.3 the pair

$214 \mathrm{H}=(\mathrm{X}, \varepsilon)$ isn't a fuzzy hypergraph on the $\mathrm{X}$ set. Figure (1) shows the fuzzy relations $\mu_{\mathrm{A}}, \mu_{\mathrm{B}}$ with

215 sets $\mu_{\mathrm{A}_{0.6}}, \mu_{\mathrm{B}_{0.6}}$.

216 Now we define under Relation $\mu_{\mathrm{c}}$ on $\mathrm{X}$ set. $\mu_{\mathrm{c}}$ a set of numbers close to 0.

$$
\mu_{\mathrm{c}}(x)=\left\{\begin{array}{ll}
0.9 & \text { where } x=1 \\
0.8 & \text { where } x=2 \\
0.7 & \text { where } x=3 \\
0.6 & \text { where } x=4 \\
0.5 & \text { where } x=5 \\
0.4 & \text { where } x=6 \\
0.3 & \text { where } x=7 \\
0.1 & \text { where } x=8 \\
0 & \text { where } x=9 \\
0 & \text { where } x=10
\end{array} \quad \mu_{\mathrm{c}}: \mathrm{X} \rightarrow[0,1]\right.
$$

217 If $\mathrm{E}=\left\{\mu_{\mathrm{A}}, \mu_{\mathrm{C}}\right\}$ then $\mathrm{X}=\operatorname{supp} \mu_{\mathrm{A}} \mathrm{U} \operatorname{supp} \mu_{c}=\{1,2,3,4,5,6,7,8,9,10\}$, by Definition 2.3 the pair $218 \mathrm{H}=(\mathrm{X}, \mathrm{E})$ is a fuzzy hypergraph on the $\mathrm{X}$ set.

\section{Methodology}

221 In hierarchical structures, not all the properties that affect classification are considered at the same 222 time. This problem-solving method actually simplifies the problem by ignoring some features, and 
223 then the problem-solving pattern is gradually modified at different levels. Finally, the main 224 problem, which is usually complex, is solved.

225 The proposed method in this paper provides the possibility of classification, taking into account 226 all the effective classification features simultaneously.

227 Defining the structure of classes is one of the main challenges in classifying elements with the 228 simultaneous impact of several properties. In this method, granular structure based on fuzzy 229 hypergraphs is defined to create the class structure. The proposed granular structure is very flexible 230 based on the classes defined in each of the properties. This flexible structure, in addition to 231 increasing the accuracy of decision-making at border points, also has the ability to classify 232 elements with high dispersion of properties and the least similarity.

233 The definition of classes in set $\mathrm{X}$ derives from the concept of these classes in each set of properties 234 of the elements of $\mathrm{X}$ set.

235 Finally, the proposed methods implemented in classifying 50,000 buildings to determine the 236 seismic risk level by considering the simultaneous impact of 10 properties.

237 Definition 3.1 Suppose $\mathrm{X}=\left\{\left(x_{1}, x_{2}, \ldots, x_{n}\right) \mid x_{i} \in \mathrm{X}_{i}, \mathrm{i}=1,2, \ldots, \mathrm{n}\right\}$ is a finite set. So that each element of $\mathrm{X}$ 238 has $\mathrm{n}$ properties. $\mathrm{X}_{\mathrm{i}}$ are sets of property values.

239 let $\mathrm{K}_{1}, \mathrm{~K}_{2}, \ldots, \mathrm{K}_{\mathrm{m}}$ are $\mathrm{m}$ title classes on set $\mathrm{X}$. Note that at this stage there is no precise definition 240 for the classes on the set $\mathrm{X}$.

241 Each $E_{i j}$ class is the concept of $K_{j}$ class on the $X_{j}$ property for $i=1,2, \ldots, n, j=1,2, \ldots, m$. We define 242 the E matrix: 


$$
\mathrm{E}=\left(\begin{array}{ccc}
\mathrm{E}_{11} & \mathrm{~K} & \mathrm{E}_{1 m} \\
\mathrm{M} & \mathrm{O} & \mathrm{M} \\
\mathrm{E}_{n 1} & \mathrm{~L} & \mathrm{E}_{n m}
\end{array}\right)
$$

244 The elements of E matrix in each row are the classes defined on properties value set. For example,

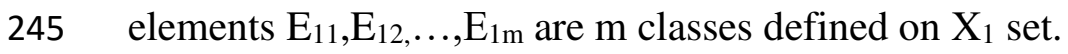

246 Lemma 3.2 $\bigcup_{j=1}^{m} E_{i j}=X_{i}$ where $E_{i j}$ are clases on sets $X_{i}, i=1,2, \ldots, n$ (sets located in a row).

247 Proof:

248 From Definition $3.1, \mathrm{E}_{\mathrm{ij}} \subseteq \mathrm{X}_{\mathrm{i}}$ for any $\mathrm{i}=1,2, \ldots, \mathrm{n}, \mathrm{j}=1,2, \ldots, \mathrm{m}$, thus $\bigcup_{\mathrm{j}=1}^{\mathrm{m}} \mathrm{E}_{\mathrm{ij}} \subseteq \mathrm{X}_{\mathrm{i}}$

249 Conversely, since for any $\mathrm{i}=1,2, \ldots, \mathrm{n}, \mathrm{j}=1,2, \ldots, \mathrm{m}, \mathrm{E}_{\mathrm{ij}}$ sets are classes defined on $\mathrm{X}_{\mathrm{i}}$ sets so:

$$
\forall \mathrm{a} \in \mathrm{X}_{\mathrm{i}} \exists \mathrm{t} \in\{1,2, \ldots, \mathrm{m}\} \text { such that } \mathrm{a} \in \mathrm{E}_{\mathrm{it}} \text {, then } \mathrm{X}_{\mathrm{i}} \subseteq \mathrm{\bigcup}_{\mathrm{j}=1}^{\mathrm{m}} \mathrm{E}_{\mathrm{ij}} \text {. }
$$

251 Combining (I), (II) we have $\bigcup_{j=1}^{m} \mathrm{E}_{\mathrm{ij}}=\mathrm{X}_{\mathrm{i}}$ for $\mathrm{i}=1,2, \ldots, \mathrm{n}$.

252 Lemma 3.3 The pair $\mathrm{H}_{\mathrm{i}}=\left(\mathrm{X}_{\mathrm{i}}, \mathrm{E}_{\mathrm{i}}\right)$ is hypergraph on $\mathrm{X}_{\mathrm{i}}$ sets, when $\mathrm{E}_{\mathrm{i}}=\left\{\mathrm{E}_{\mathrm{ij}} \mid \mathrm{E}_{\mathrm{ij}} \neq \varnothing, \mathrm{j}=1,2, \ldots, \mathrm{m}\right\}$

253 and $\mathrm{i}=1,2, \ldots, \mathrm{n}$.

254 Proof:

255

From Lemma $3.2, \bigcup_{j=1}^{m} E_{i j}=X_{i}$ for $i=1,2, \ldots, n$, by Definition 2.2 the pair $H_{i}=\left(X_{i}, E_{i}\right)$ is

256 hypergraph on $\mathrm{X}_{\mathrm{i}}$ sets.

257 
258 Definition 3.4 Corresponding to matrix $\mathrm{E}$ in the Definition 3.1, we define $\theta_{x}$ matrix for all $x \in \mathrm{X}$,

259 as follows:

260

$$
\theta_{x}=\left(\begin{array}{ccc}
\theta_{11}\left(x_{1}\right) & \mathrm{K} & \theta_{1 m}\left(x_{1}\right) \\
\mathrm{M} & \mathrm{O} & \mathrm{M} \\
\theta_{n 1}\left(x_{\mathrm{n}}\right) & \mathrm{L} & \theta_{n m}\left(x_{\mathrm{n}}\right)
\end{array}\right)
$$

261 such that:

$$
\theta_{i j}\left(x_{i}\right)=\left\{\begin{array}{ccc}
\mu_{i j}\left(x_{i}\right) & \text { where } & x_{i} \in \mathrm{E}_{i j} \\
-\mu_{i j}^{c}\left(x_{i}\right) & \text { where } & x_{i} \notin \mathrm{E}_{i j}
\end{array}\right.
$$

264 where:

265

$$
\mu_{i j}: \mathrm{E}_{i j} \rightarrow[0,1], \mu_{i j}^{c}: \mathrm{E}_{i j}^{\mathrm{c}} \rightarrow[0,1], \mathrm{E}_{i j}^{\mathrm{c}}=\mathrm{X}_{i}-\mathrm{E}_{i j}
$$

$$
\text { for } \mathrm{i}=1,2, \ldots, \mathrm{n}, \mathrm{j}=1,2, \ldots, \mathrm{m} \text {. }
$$

269 For each $e \in \mathrm{E}_{i j}$, value of the $\mu_{i j}(e)$ function is called e-membership degree in the $\mathrm{E}_{\mathrm{ij}}$ set, also the 270 value of the $\mu_{i j}^{c}(e)$ function is called e-membership degree in the $\mathrm{E}_{i j}^{c}$ set. The elements of the 271 matrix are functions.

272

273 Definition 3.5 The $\mathrm{j}^{\text {th }}$ score of the element $x \in \mathrm{X}=\left\{\left(x_{1}, x_{2}, x_{3}, \ldots, x_{n}\right) \mid x_{i} \in \mathrm{X}_{i}, \mathrm{i}=1,2, \ldots, \mathrm{n}\right\}$ is a special 274 number, that can be calculated from the matrix $\theta_{x}$ as follows: 
276 For example, the sum of the elements of the first column in the matrix $\theta_{x}$ is score $_{1}(x)$.

277 Definition 3.6 Let $x \in \mathrm{X}=\left\{\left(x_{1}, x_{2}, \ldots, x_{n}\right) \mid x_{i} \in \mathrm{X}_{i}, \mathrm{i}=1,2, \ldots, \mathrm{n}\right\}$, from Definition 3.5 we define:

$$
\mathrm{L}_{m+1}=\left\{x \in \mathrm{X} \mid \operatorname{score}_{\mathrm{j}}(x)<0 \text { for all } \mathrm{j}=1,2, . ., \mathrm{m}\right\} .
$$

282 Each of sets $\mathrm{L}_{\mathrm{j}}$ are granules. By Definition $2.2 \mathrm{H}=(\mathrm{X}, \mathrm{L})$ is a hypergraph on $\mathrm{X}$. The proposed 283 granular structure is shown in Figure (2).

284 The elements of $\mathrm{L}_{1}, \mathrm{~L}_{2}, \ldots, \mathrm{L}_{m}$ granules have at least a $\operatorname{score}_{\mathrm{j}}(x) \geq 0$ value (see Figure (2)). Zone A 285 contains an element of set $\mathrm{X}$ that has no value $\operatorname{score}_{\mathrm{j}}(x) \geq 0$ and only has $\operatorname{score}_{\mathrm{j}}(x)<0$ values (set $286 \mathrm{~L}_{\mathrm{m}+1}$ ).In other words, they are not in any granule (class). Zone B is composed of elements that 287 have a $\operatorname{score}_{\mathrm{j}}(x) \geq 0$ in all granules (classes). 


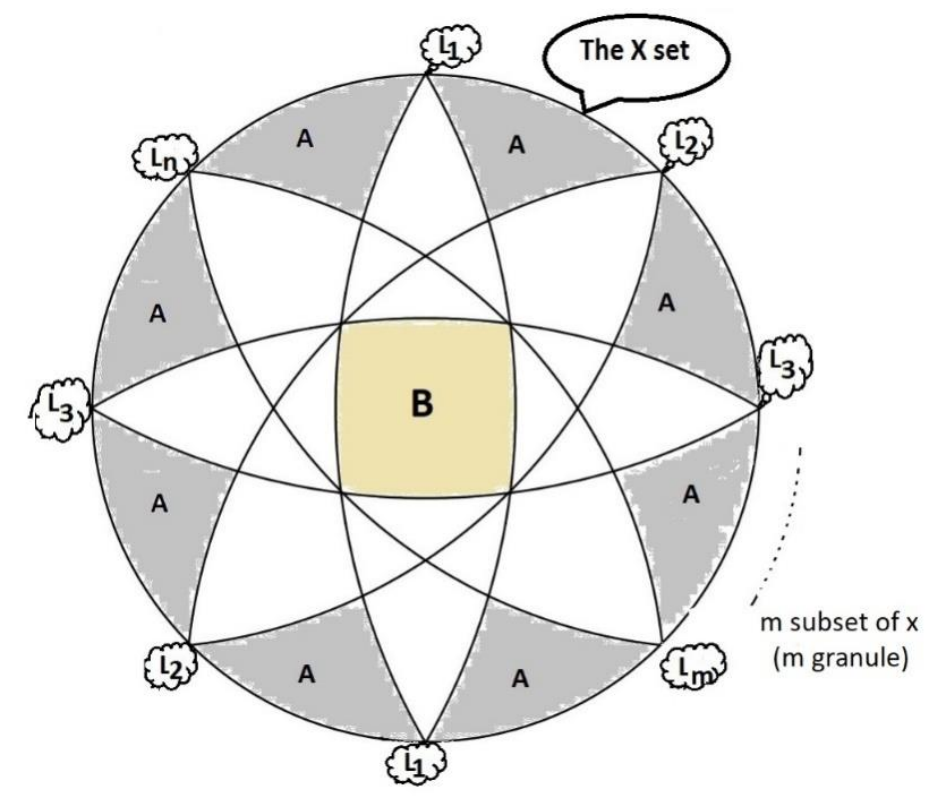

289

Figure (2): The proposed granular structure

290

291 Definition 3.7 Let $x \in \mathrm{X}=\left\{\left(x_{1}, x_{2}, \ldots, x_{n}\right) \mid x_{i} \in \mathrm{X}_{i}, \mathrm{i}=1,2, \ldots, \mathrm{n}\right\}$, based on the score $_{\mathrm{j}}(x)$ for $=1,2, \ldots, \mathrm{m}$

292 defined several DoM score $_{j}$ values (degree of membership) or DoNM score $_{j}$ values (non-membership)

293 as follows:

294 if $\operatorname{score}_{\mathrm{j}}(x) \geq 0$ then $\operatorname{DoM}_{\text {score }_{\mathrm{j}}}(x)=\mu\left(\operatorname{score}_{\mathrm{j}}(x)\right)$ where $\mu: \mathrm{L}_{j} \rightarrow[0,1]$ for $\mathrm{j}=1,2, \ldots, \mathrm{m}$.

295 if $\operatorname{score}_{\mathrm{j}}(x)<0$ then $\operatorname{DoNM}_{\text {score }_{\mathrm{j}}}(x)=\eta\left(\operatorname{score}_{\mathrm{j}}(x)\right)$ where $\eta: \mathrm{L}_{m+1} \rightarrow[0,1]$ for $\mathrm{j}=1,2, \ldots, \mathrm{m}$.

296 Definition 3.8 Let $x \in \mathrm{X}=\left\{\left(x_{1}, x_{2}, \ldots, x_{n}\right) \mid x_{i} \in \mathrm{X}_{i}, \mathrm{i}=1,2, \ldots, \mathrm{n}\right\}$ from Definition 3.7 we define:

$$
\operatorname{DoM}(x)=\max \left\{\operatorname{DoM}_{\text {score }_{j}}(x) \text { for } \mathrm{j}=1,2, \ldots, \mathrm{m}\right\}
$$

$$
\mathrm{K}_{\mathrm{j}}=\left\{x \mid \operatorname{DoM}(x)=\operatorname{DoM}_{\text {score }_{\mathrm{j}}}(x)\right\} \text { for } \mathrm{j}=1,2, \ldots, \mathrm{m}
$$




$$
\operatorname{DoNM}(x)=\min \left\{\operatorname{DoNM}_{\text {score }_{\mathrm{j}}}(x) \text { for } \mathrm{j}=1,2, \ldots, \mathrm{m}\right\}
$$

$$
\mathrm{K}_{m+1}=\{x \mid \exists \operatorname{DoNM}(\mathrm{x})\}
$$

303 By Definition 3.7, a fuzzy hypergraph on the set $\mathrm{X}$ is defined. The elements of the set $\mathrm{X}$ that have 304 the highest $\operatorname{DoM}_{\text {score }_{j}}(x)$ value form the subset, which in turn defines $\mathrm{K}_{\mathrm{j}}$ class in Definition 3.1. 305 This way of constructing subsets defines the granular structure, which is considered as a class. The 306 other values of $\operatorname{DoM}_{\text {score }_{j}}(x)$ indicate the belonging of element $x \in \mathrm{X}$ to other classes, with 307 different degrees of membership. The absence of a value of $\operatorname{DoM}_{\text {score }_{j}}(x)$ for $x \in \mathrm{X}$ indicates that 308 the property values are too scattered. Such elements simply have different degrees of $309 \operatorname{DoNM}_{\text {score }_{\mathrm{j}}}(x)$ non-belonging to classes. The set of all these elements are considered a subset of $310 \mathrm{X}$ as a class $\mathbf{K}_{m+1}$ (the smallest degree of non-belonging $\operatorname{DoNM}_{\text {score }_{\mathrm{j}}}(x)$ ).

311 Lemma 3.9 $\mathrm{X}=\bigcup_{\mathrm{j}=1}^{m+1} \mathrm{~K}_{\mathrm{j}}$ where $\mathrm{K}_{\mathrm{j}}$ are classes on set $\mathrm{X}$.

\section{Proof:}

313 Let $x \in \bigcup_{\mathrm{j}=1}^{m+1} \mathrm{~K}_{\mathrm{j}} \Rightarrow \exists 1 \leq \mathrm{t} \leq m+1$ such that $x \in \mathrm{K}_{\mathrm{t}} \subset \mathrm{X} \Rightarrow \bigcup_{\mathrm{j}=1}^{m+1} \mathrm{~K}_{\mathrm{j}} \subseteq \mathrm{X}$.

\section{Conversely}

\section{Case 1:}


316 For any $x \in \mathrm{X}$ there exists $\mathrm{t} \in\{1,2, \ldots, \mathrm{m}\}$ such that $\operatorname{score}_{\mathrm{t}}(x) \geq 0$. From Definition 3.8 $\operatorname{DoM}(x)$

317 value is defined and $x \in \mathrm{K}_{\mathrm{t}}$

318 then

$319 \quad x \in \bigcup_{\mathrm{j}=1}^{m} \mathrm{~K}_{\mathrm{j}} \Rightarrow \mathrm{X} \subseteq \mathrm{\bigcup}_{\mathrm{j}=1}^{m} \mathrm{~K}_{\mathrm{j}} \subseteq \bigcup_{\mathrm{j}=1}^{m+1} \mathrm{~K}_{\mathrm{j}}$.

320 Case 2:

$321 \operatorname{score}_{\mathrm{t}}(x)<0$ for any $\mathrm{t} \in\{1,2, \ldots, \mathrm{m}\}$ by Definition $3.6 x \in \mathrm{L}_{\mathrm{m}+1}$. From Definition 3.8 $\operatorname{DoNM}(x)$

322 value is defined and $x \in \mathrm{K}_{\mathrm{m}+1}$

323 then

324

$$
x \in \bigcup_{\mathrm{j}=1}^{m+1} \mathrm{~K}_{\mathrm{j}} \Rightarrow \mathrm{X} \subseteq \bigcup_{\mathrm{j}=1}^{m+1} \mathrm{~K}_{\mathrm{j}} .(\mathrm{V})
$$

325 By (III), (IV), (V) we have $\mathrm{X}=\bigcup_{\mathrm{j}=1}^{m+1} \mathrm{~K}_{\mathrm{j}}$. 


\begin{tabular}{|c|c|}
\hline $\begin{array}{c}\text { By } \\
\text { Def :3.1 }\end{array}$ & $\begin{array}{l}\text { Determine the value sets for the properties of the elements of the set } X \text {, under } \\
\text { the title of sets } X_{i} \text {. }\end{array}$ \\
\hline $\begin{array}{c}\text { By } \\
\text { Def :3.1 }\end{array}$ & Define the $\mathrm{X}$ set, base on the $\mathrm{X}_{i}$ sets, $\mathrm{X}=\left\{\left(x_{1}, x_{2}, x_{3}, \ldots, x_{n}\right) \mid x_{i} \in \mathrm{X}_{i}\right\}$. \\
\hline $\begin{array}{c}\text { By } \\
\text { Def :3.1 }\end{array}$ & $\begin{array}{l}\text { Expression of } \mathrm{m} \text {-class titles, to classify the elements of set } \mathrm{X} \text { under the } \\
\text { heading of classes: } \mathrm{K}_{1}, \mathrm{~K}_{2}, \mathrm{~K}_{3}, \ldots, \mathrm{K}_{m} \text {. }\end{array}$ \\
\hline $\begin{array}{c}\text { By } \\
\text { Def :3.1 }\end{array}$ & $\begin{array}{l}\text { Implement the concept of classes } \mathrm{K}_{\mathrm{j}} \text { on each set of values as sets } \mathrm{E}_{\mathrm{ij}} \subset \mathrm{X}_{\mathrm{i}} \text { and } \\
\text { form classes on sets of values. }\end{array}$ \\
\hline $\begin{array}{c}\text { By } \\
\text { Def :3.1 }\end{array}$ & Formation of matrix $\mathrm{E}$ based on classes $\mathrm{E}_{\mathrm{ij}}$. \\
\hline $\begin{array}{c}\text { By } \\
\text { Def :3.4 }\end{array}$ & Definition of membership functions $\mu_{i j}$ on classes $\mathrm{E}_{\ddot{j}}$ as $\mu_{i j}: \mathrm{E}_{\ddot{j}} \rightarrow[0,1]$. \\
\hline $\begin{array}{c}\text { By } \\
\text { Def :3.4 }\end{array}$ & $\begin{array}{l}\text { Definition of membership functions } \mu_{i j}^{c} \text { on sets } \mathrm{E}_{i j}^{c} \text { as follows: } \\
\qquad \mu_{i j}^{c}: \mathrm{E}_{i j}^{c} \rightarrow[0,1] \text { where } \mathrm{E}_{i j}^{c}=\mathrm{X}_{i}-\mathrm{E}_{i j}\end{array}$ \\
\hline $\begin{array}{c}\text { By } \\
\text { Def :3.4 }\end{array}$ & Formation of matrix $\theta_{x}$ for elements of set $\mathrm{X}$. \\
\hline $\begin{array}{c}\text { By } \\
\text { Def :3.5 }\end{array}$ & Form a matrix $\theta_{x}$ to score the elements of set $\mathrm{X}$ as $\operatorname{score}_{j}(x)$ \\
\hline $\begin{array}{c}\text { By } \\
\text { Def :3.6 }\end{array}$ & $\begin{array}{l}\text { Form } L_{j} \subseteq X \text { sets so that } H=(X, L) \text { is a hypergraph on the set } X \text {. } \\
\qquad L=\left\{L_{1}, L_{2}, L_{3}, \ldots, L_{m+1}\right\}\end{array}$ \\
\hline $\begin{array}{c}\text { By } \\
\text { Def :3.7 }\end{array}$ & $\begin{array}{l}\text { Define functions } \mu, \eta \text { on sets } \mathrm{L}_{1}, \mathrm{~L}_{2}, \mathrm{~L}_{3}, \ldots, \mathrm{L}_{m+1} \text { to determine values as follows: } \\
\qquad \operatorname{DoNM}_{s c a r e}(x), \mathrm{DoM}_{\text {sore }}(x)\end{array}$ \\
\hline $\begin{array}{c}\text { By } \\
\text { Def :3.8 }\end{array}$ & $\begin{array}{l}\text { Determine the values of } \operatorname{DoNM}(x), \operatorname{DoM}(x) \text { to define a fuzzy hypergraph, the } \\
\text { structure of classes } \mathrm{K}_{1}, \mathrm{~K}_{2}, \mathrm{~K}_{3}, \ldots, \mathrm{K}_{m+1} \text { and the degree of membership. }\end{array}$ \\
\hline
\end{tabular}

Figure (3): Diagram of the proposed method 
329 Lemma $3.1 \mathrm{H}=(\mathrm{X}, \mathrm{E})$ is fuzzy hypergraph on $\mathrm{X}$ where $\mathrm{E}=\left\{\mathrm{K}_{\mathrm{j}} \mid \mathrm{K}_{\mathrm{j}} \neq \varnothing, \mathrm{j}=1,2, \ldots, m+1\right\}$.

330 Proof:

331 By Lemma 3.9 $\mathrm{X}=\bigcup_{\mathrm{j}=1}^{m+1} \mathrm{~K}_{\mathrm{j}}$, from Definition 2.3 pair $\mathrm{H}=(\mathrm{X}, \mathrm{E})$ is a fuzzy hypergraph on the set $\mathrm{X}$.

332 Thus, the flexural granular structure is defined based on fuzzy hypergraphs that have 333 the ability to classify data with the least similarity. An example is given below which 334 uses the proposed method to assess the seismic vulnerability of buildings.

335 The steps of the proposed method are shown in Figure (3). In this diagram $i=1,2, \ldots, n, j=1,2, \ldots, m$.

\subsection{Validation}

In 1936, Fischer, field-examined 150 irises (43). As shown in Table (1), he used his intuitive experience to classify these flowers into three categories based on four characteristics (see Table (2)). For validation, iris flowers were examined and classified by Fisher (data and results of the

341 study are available) and then classified again using the proposed method.

Table (1): Types of irises

\begin{tabular}{|c|c|}
\hline Row & Flower Name \\
\hline 1 & Setosa \\
\hline 2 & Virginica \\
\hline 3 & Versicolor \\
\hline
\end{tabular}

Table (2): Characteristics of flowers

\begin{tabular}{|c|c|c|}
\hline Row & Characteristics & Size $(\mathrm{cm})$ \\
\hline 1 & Sepal length & $\{4.3,4.4, \ldots, 7.9\}$ \\
\hline 2 & Sepal width & $\{2,2.1, \ldots, 4.4\}$ \\
\hline 3 & Petal length & $\{1,1.1, \ldots, 6.9\}$ \\
\hline 4 & Petal Width & $\{0.1,0.2, \ldots, 2.5\}$ \\
\hline
\end{tabular}


343 The collection of flowers are defined and introduced as follows:

$$
\mathrm{X}=\left\{\left(x_{1}, x_{2}, x_{3}, x_{4}\right) \mid x_{j} \in \mathrm{X}_{j}, \mathrm{j}=1, \ldots, 4\right\}
$$

345 such that:

$$
X_{1}=\{4.3,4.4, \ldots, 7.9\}, X_{2}=\{2,2.1, \ldots, 4.4\}, X_{3}=\{1,1.1, \ldots, 6.9\}, X_{4}=\{0.1,0.2, \ldots, 2.5\}
$$

347 In the next step, we implement the concept of the classes in Table (1) for each of the properties 348 of Table (2) as sets $\mathrm{X}_{\mathrm{i}}$. With this implementation, classes (sets $\mathrm{E}_{\mathrm{ij}}$ ) are defined in each property. 349 Now, according to the definition of 3.1, we form a matrix E:

350

$$
\mathrm{E}=\left(\begin{array}{cccc}
\{4.3,4.4, \ldots, 5.8\} & \{4.9,5.0, \ldots, 7.0\} & \{4.9,5.0, \ldots, 7.9\} \\
\{2.0,2.1, \ldots, 3.4\} & \{2.2,2.3, \ldots, 3.8\} & \{2.3,2.4, \ldots, 4.4\} \\
\{1.0,1.1, \ldots, 1.9\} & \{3.0,3.1, \ldots, 5.1\} & \{4.5,4.6, \ldots, 6.9\} \\
\{0.1,0.2, \ldots, 0.6\} & \{1.0,1.1, \ldots, 1.8\} & \{1.4,1.5, \ldots, 2.5\}
\end{array}\right)
$$

\section{$352 \quad$ 3.1.1 Description}

353 The elements of the first row of the matrix, the classes defined on the set of values of the sepals, 354 are one of the four characteristics of the lily (set $X_{1}$ ). This classification is defined based on Fisher's 355 intuitive observations (the other lines are the same). These classes define $\mathrm{H}_{1}=\left(\mathrm{X}_{1}, \mathrm{E}_{1}\right), \mathrm{H}_{2}=\left(\mathrm{X}_{2}, \mathrm{E}_{2}\right)$, $356 \mathrm{H}_{3}=\left(\mathrm{X}_{3}, \mathrm{E}_{3}\right), \mathrm{H}_{4}=\left(\mathrm{X}_{4}, \mathrm{E}_{4}\right)$, hypergraphs on four sets of Fisher values (Lemma 3.3), respectively. The 357 sepal length property is classified $\mathrm{E}_{11}, \mathrm{E}_{12}, \mathrm{E}_{13}$ such that:

$$
\mathrm{E}_{11}=\{4.3,4.4, \ldots, 5.8\}, \mathrm{E}_{12}=\{4.9,5.0, \ldots, 7.0\}, \mathrm{E}_{13}=\{4.9,5.0, \ldots .7 .9\}
$$

359 Clearly $E_{1 j} \neq \varnothing$, for $\mathrm{j}=1,2,3$ and $\mathrm{E}_{1}=\bigcup_{\mathrm{j}=1}^{3} \mathrm{E}_{1 \mathrm{j}}$ (Lemma 3.3). 
Each class represents a type of flower.

361 Each of the classes in Table (2) represents a type of iris. The proposed method for determining the 362 structure and members of each type of iris defines a fuzzy hypergraph on the X set. Based on 363 Definition 3.4, we form a matrix of $\theta_{x}$ for each iris flower. For this purpose, we define fuzzy 364 membership functions $\mu_{i j}(x), \mu_{i j}^{c}(x)$ on sets $\mathrm{E}_{i j}^{c}, \mathrm{E}_{i j}$.

$$
\mu_{i j}^{c}(x): \mathrm{E}_{i j}^{c} \rightarrow[0,1] \text { such that } \mu_{i j}^{c}(x)=0
$$

$$
\mu_{i j}(x): \mathrm{E}_{i j} \rightarrow[0,1]
$$

$$
\begin{aligned}
& \int \frac{\left(x-\operatorname{mode}_{\mathrm{E}_{i j}}\right)}{\left(\operatorname{mode}_{\mathrm{E}_{i j}}-\min _{\left.\mathrm{E}_{i j}\right)}\right)}+1 \quad \text { where } \quad x \leq \operatorname{mode}_{\mathrm{E}_{i j}}, \operatorname{mode}_{\mathrm{E}_{i j}} \neq \min _{\mathrm{E}_{i j}} \\
& \mu_{i j}(x)=\left\{\frac{\left(x-\operatorname{mode}_{\mathrm{E}_{i j}}\right)}{\left(\operatorname{mode}_{\mathrm{E}_{i j}}-\max _{\mathrm{E}_{i j}}\right)}+1 \quad \text { where } x>\operatorname{mode}_{\mathrm{E}_{i j}}, \operatorname{mode}_{\mathrm{E}_{i j}} \neq \max _{\mathrm{E}_{i j}}\right. \\
& \operatorname{mode}_{\mathrm{E}_{i j}}=\min _{\mathrm{E}_{i j}} \\
& 0.00001 \times\left(x-\operatorname{mode}_{\mathrm{E}_{i j}}\right)+1 \quad \text { where or } \\
& \operatorname{mode}_{\mathrm{E}_{i j}}=\max _{\mathrm{E}_{i j}} \\
& i=1,2,3,4 \quad j=1,2,3
\end{aligned}
$$

368 It is clear that mode $E_{\mathrm{ij}}$ is a member of $\mathrm{E}_{i j}$ with the most repetition.

369 Now, using Definition 3.5, the values of $\operatorname{score}_{\mathrm{j}}(x) \geq 0$ for the elements of set $\mathrm{X}$ are calculated. To

370 better clarify the content, a sample of iris, which is shown with the symbol $x$, has been placed in

371 the process of the proposed method. Consider the sample iris with specifications

$372 x=(5.1,3 \cdot 5,1.4,0.2)$. We form matrix $\theta_{\mathrm{x}}$ based on membership functions $\mu_{i j}(x)$ and $\mu_{i j}^{c}(x)$ : 


$$
\theta_{x}=\left(\begin{array}{ccc}
0.875 & 0.95 & 0.967 \\
0.643 & 0 & 0.375 \\
0.8 & 0 & 0 \\
1 & 0 & 0
\end{array}\right)
$$

376 Then, by Defining 3.5, the values of score $_{\mathrm{j}}(x)$ are calculated:

377

$$
\begin{aligned}
& \text { score }_{1}(x)=3.318 \\
& \text { score }_{2}(x)=0.95 \\
& \text { score }_{3}(x)=1.341
\end{aligned}
$$

378 Now by Defining 3.7 and using the membership function $\mu$, the values of $\operatorname{DoM}_{\text {score }_{\mathrm{j}}}$ for $\mathrm{j}=1,2,3$

379 are calculated.

$$
\mu:[0,4] \rightarrow[0,1] \text { such tath } \mu(x)=x / 4
$$

$$
\operatorname{DoM}_{\text {score }_{1}}=0.829464286
$$$$
\text { DoM }_{\text {score }_{2}}=0.2375
$$$$
\text { DoM }_{\text {score }_{3}}=0.33512931
$$

382 According to the Definition 3.8, the sample iris belongs to class $\mathrm{K}_{1}$ (see Table (3)) with a 383 membership degree of 0.829464286. In Table (4), the performed classification and Fisher's 384 experimental classification are given and compared for some samples of irises.

385 In samples 1-2-3-54-56-59-60-61, the experimental results are consistent with the classification of 386 the proposed method. This agreement is more than $90 \%$ in 150 samples. In sample 58, the 387 experimental results do not match the classification of the proposed method. But the degree of 388 membership to each class is very low, and this is due to the over-dispersion of the sample property 
389 values. The experimental results do not match to the classification of the proposed method for No.

392

\begin{tabular}{|c|c|c|}
\hline Row & Flower Name & $\begin{array}{c}\text { Class } \\
393\end{array}$ \\
\hline 1 & Setosa & $\mathrm{K}_{1}$ \\
394 \\
\hline 2 & Virginica & $\mathrm{K}_{2}$ \\
395 \\
\hline 3 & Versicolor & $\mathrm{K}_{3}$ \\
\hline
\end{tabular}

Table (4): Flower Sample

\begin{tabular}{|c|c|c|c|c|c|c|c|c|c|c|}
\hline \multirow{2}{*}{ 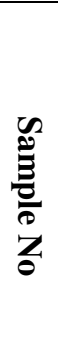 } & \multicolumn{4}{|c|}{ Flower characteristics } & \multirow{2}{*}{$\begin{array}{l}\text { Flower type } \\
\text { based on } \\
\text { experiment } \\
\text { al method }\end{array}$} & \multirow{2}{*}{$\begin{array}{l}\text { Flower type } \\
\text { based on } \\
\text { proposed } \\
\text { method }\end{array}$} & \multirow{2}{*}{$\begin{array}{l}\text { Degree of } \\
\text { belonging } \\
\text { to the } \\
\text { class }\end{array}$} & \multicolumn{3}{|c|}{ Class membership rate } \\
\hline & $\begin{array}{l}\text { Sepal } \\
\text { length }\end{array}$ & $\begin{array}{l}\text { Sepal } \\
\text { width }\end{array}$ & $\begin{array}{l}\text { Petal } \\
\text { length }\end{array}$ & $\begin{array}{l}\text { Petal } \\
\text { Width }\end{array}$ & & & & Iris-setosa & $\begin{array}{c}\text { Iris- } \\
\text { virginica }\end{array}$ & $\begin{array}{c}\text { Iris- } \\
\text { versicolor }\end{array}$ \\
\hline 1 & 5.1 & 3.5 & 1.4 & 0.2 & Iris-setosa & Iris-setosa & 0.829464286 & 0.829464286 & 0.33512931 & 0.2375 \\
\hline 2 & 4.9 & 3 & 1.4 & 0.2 & Iris-setosa & Iris-setosa & 0.914285714 & 0.914285714 & 0.25 & 0.25 \\
\hline 3 & 4.7 & 3.2 & 1.3 & 0.2 & Iris-setosa & Iris-setosa & 0.757142857 & 0.757142857 & 0.1875 & 0.125 \\
\hline 53 & 6.9 & 3.1 & 4.9 & 1.5 & Iris-versicolor & Iris-virginica & 0.76329023 & 0.232142857 & 0.76329023 & 0.433333333 \\
\hline 54 & 5.5 & 2.3 & 4 & 1.3 & Iris-versicolor & Iris-versicolor & 0.679166667 & 0.09375 & 0.238146552 & 0.679166667 \\
\hline 56 & 5.7 & 2.8 & 4.5 & 1.3 & Iris-versicolor & Iris-versicolor & 0.8625 & 0.209821429 & 0.627155172 & 0.8625 \\
\hline 58 & 4.9 & 2.4 & 3.3 & 1 & Iris-versicolor & Iris-setosa & 0.25 & 0.25 & 0.0625 & 0 \\
\hline 59 & 6.6 & 2.9 & 4.6 & 1.3 & Iris-versicolor & Iris-versicolor & 0.733333333 & 0.214285714 & 0.570402299 & 0.733333333 \\
\hline 60 & 5.2 & 2.7 & 3.9 & 1.4 & Iris-versicolor & Iris-versicolor & 0.75 & 0.330357143 & 0.389008621 & 0.75 \\
\hline 61 & 5 & 2 & 3.5 & 1 & Iris-versicolor & Iris-versicolor & 0.333333333 & 0.25 & 0.25 & 0.333333333 \\
\hline
\end{tabular}


400 In this method, in addition to the possibility of classifying samples with any number of 401 characteristics and any amount of information scatter, it is also possible to determine the degree of 402 membership to the class. There is also a lot of flexibility in this method by selecting membership 403 functions according to the classification structure. The results of the proposed method are shown 404 in the following diagrams.

405

406

407

408

409 410

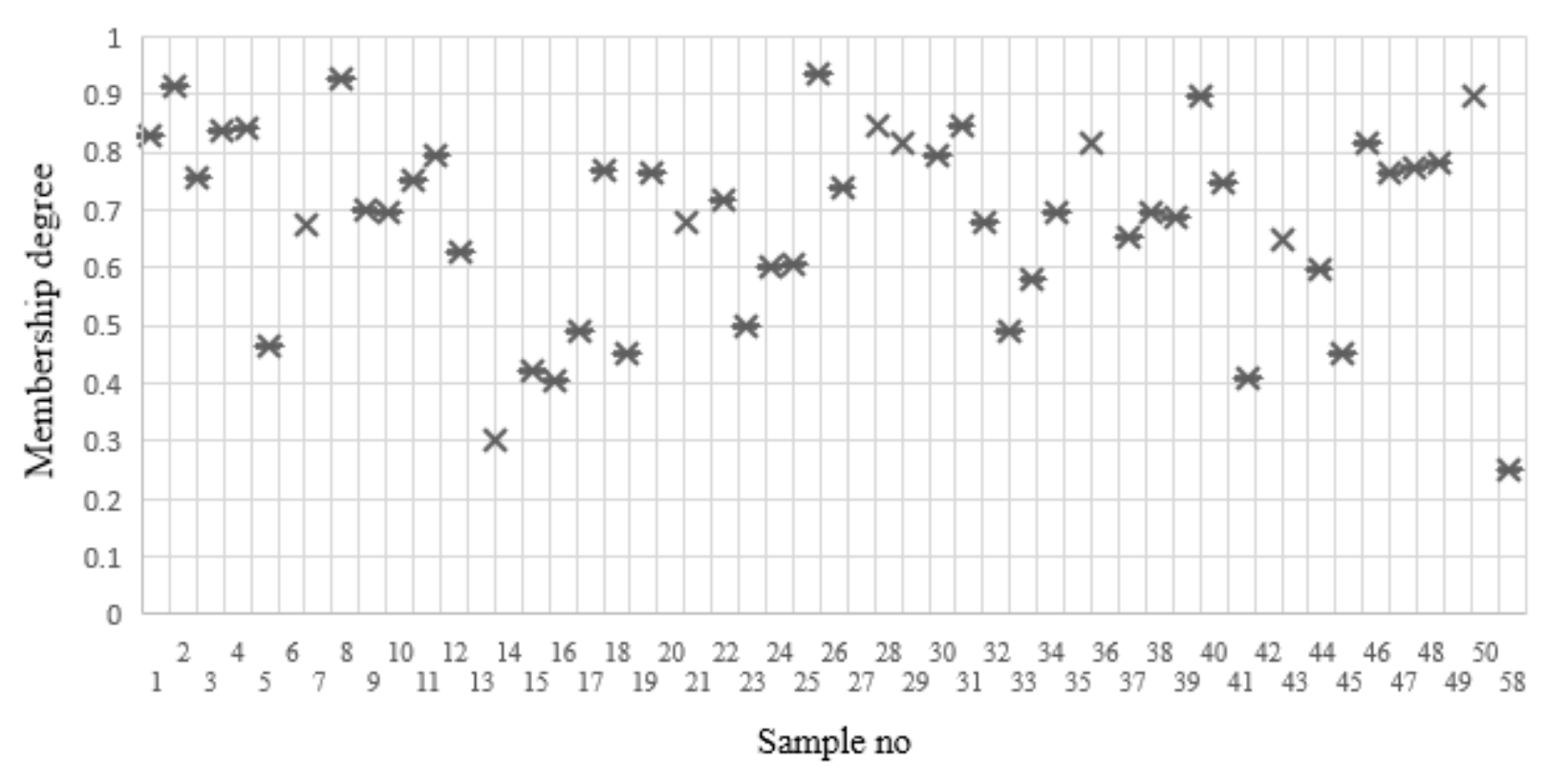

Figure (4): Setosa membership degree chart

Figure (4) shows that $95 \%$ of the elements with a membership degree of more than 0.3 are in the Iris-setosa flower class, and this shows the accuracy of the method. 


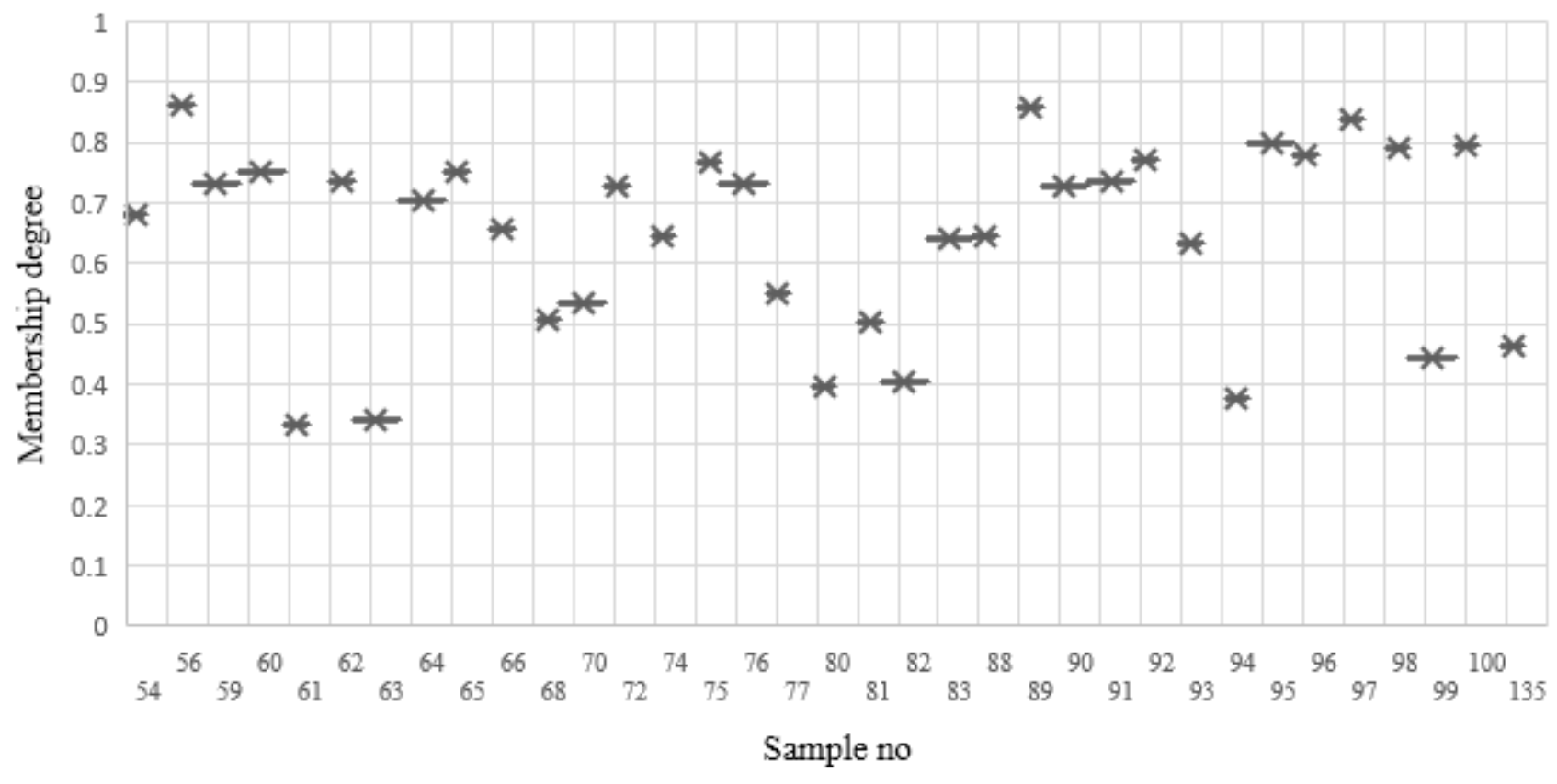

414 Figure (5) also shows that the membership of elements in the Iris-versicolor flower class is more 415 than 0.3 .

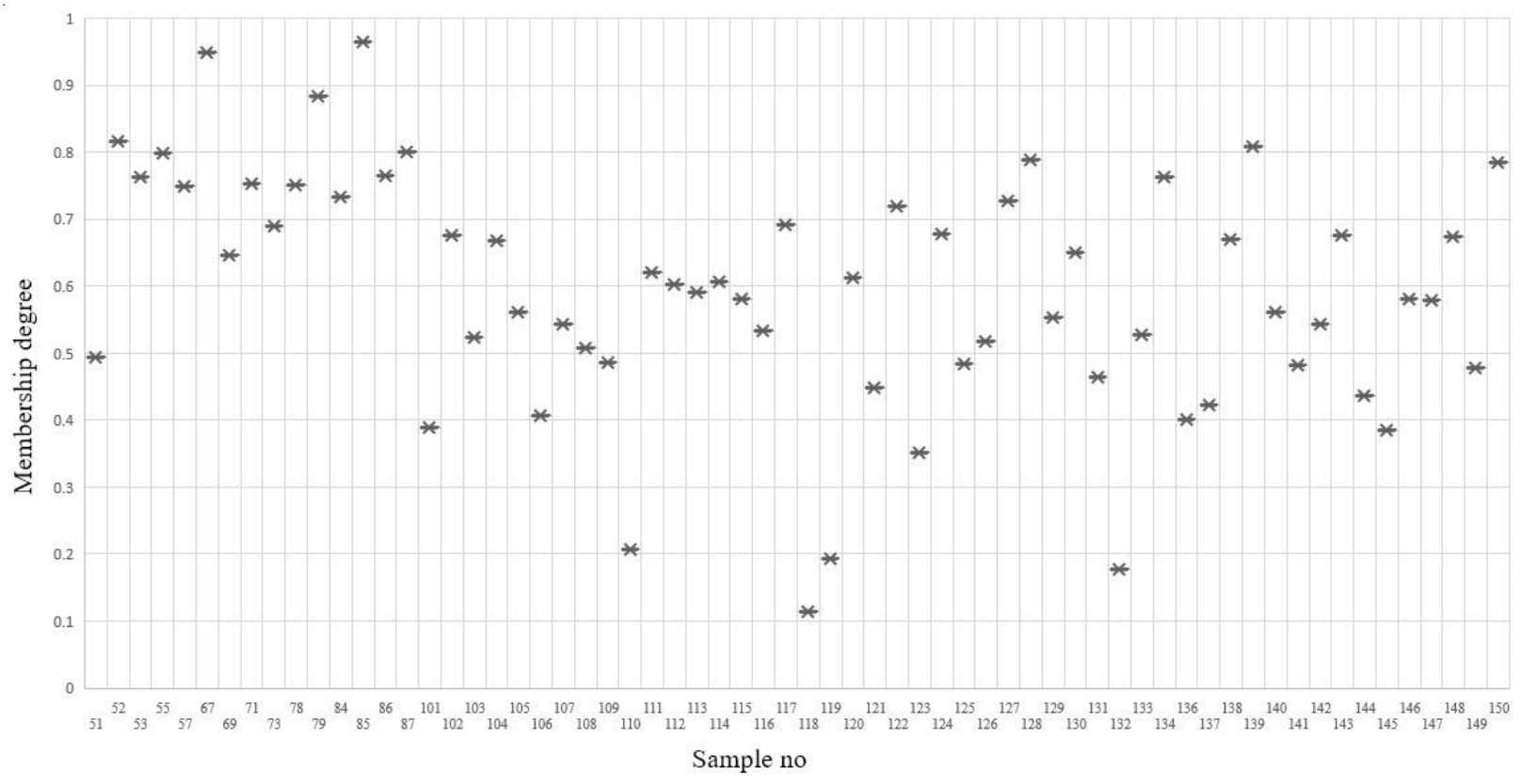


419 Figure (6) shows that a number of elements with a membership of less than 0.2 are in the Iris-

420 virginica class. This is due to the high dispersion of data, but the proposed method has the ability

421 to classify, which is one of the strengths of this method. The comparison of the classes of Table (5)

422 shows the differences between the proposed method and the results of the field study and Fisher's

423 intuitive experiences.

Table: (5): Comparison of the classes

\begin{tabular}{|c|c|c|c|c|c|c|c|c|c|c|}
\hline \multirow{2}{*}{ 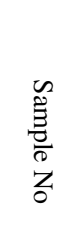 } & \multicolumn{4}{|c|}{ Flower characteristics } & \multirow{2}{*}{$\begin{array}{c}\text { Flower type } \\
\text { based on } \\
\text { experimental } \\
\text { method }\end{array}$} & \multirow{2}{*}{$\begin{array}{l}\text { Flower type } \\
\text { based on } \\
\text { proposed } \\
\text { method }\end{array}$} & \multirow{2}{*}{$\begin{array}{c}\text { Degree of } \\
\text { belonging to } \\
\text { the class }\end{array}$} & \multicolumn{3}{|c|}{ Class membership rate } \\
\hline & $\begin{array}{l}\text { Sepal } \\
\text { length }\end{array}$ & $\begin{array}{l}\text { Sepal } \\
\text { width }\end{array}$ & $\begin{array}{l}\text { Petal } \\
\text { length }\end{array}$ & $\begin{array}{l}\text { Petal } \\
\text { Width }\end{array}$ & & & & Iris-setosa & $\begin{array}{c}\text { Iris- } \\
\text { virginica }\end{array}$ & $\begin{array}{c}\text { Iris- } \\
\text { versicolor }\end{array}$ \\
\hline 51 & 7 & 3.2 & 4.7 & 1.4 & Iris-versicolor & Iris-virginica & 0.494252874 & 0.214285714 & 0.494252874 & 0.491666667 \\
\hline 52 & 6.4 & 3.2 & 4.5 & 1.5 & Iris-versicolor & Iris-virginica & 0.816810345 & 0.214285714 & 0.816810345 & 0.6 \\
\hline 53 & 6.9 & 3.1 & 4.9 & 1.5 & Iris-versicolor & Iris-virginica & 0.76329023 & 0.232142857 & 0.76329023 & 0.433333333 \\
\hline 55 & 6.5 & 2.8 & 4.6 & 1.5 & Iris-versicolor & Iris-virginica & 0.797772989 & 0.178571429 & 0.797772989 & 0.620833333 \\
\hline 57 & 6.3 & 3.3 & 4.7 & 1.6 & Iris-versicolor & Iris-virginica & 0.748347701 & 0.196428571 & 0.748347701 & 0.416666667 \\
\hline 58 & 4.9 & 2.4 & 3.3 & 1 & Iris-versicolor & Iris-setosa & 0.25 & 0.25 & 0.0625 & 0 \\
\hline 67 & 5.6 & 3 & 4.5 & 1.5 & Iris-versicolor & Iris-virginica & 0.948275862 & 0.3125 & 0.948275862 & 0.825 \\
\hline 69 & 6.2 & 2.2 & 4.5 & 1.5 & Iris-versicolor & Iris-virginica & 0.646551724 & 0 & 0.646551724 & 0.55 \\
\hline 71 & 5.9 & 3.2 & 4.8 & 1.8 & Iris-versicolor & Iris-virginica & 0.753663793 & 0.214285714 & 0.753663793 & 0.3875 \\
\hline 73 & 6.3 & 2.5 & 4.9 & 1.5 & Iris-versicolor & Iris-virginica & 0.690014368 & 0.071428571 & 0.690014368 & 0.445833333 \\
\hline 78 & 6.7 & 3 & 5 & 1.7 & Iris-versicolor & Iris-virginica & 0.751364943 & 0.25 & 0.751364943 & 0.379166667 \\
\hline 79 & 6 & 2.9 & 4.5 & 1.5 & Iris-versicolor & Iris-virginica & 0.882543103 & 0.214285714 & 0.882543103 & 0.75 \\
\hline 84 & 6 & 2.7 & 5.1 & 1.6 & Iris-versicolor & Iris-virginica & 0.732543103 & 0.142857143 & 0.732543103 & 0.4 \\
\hline 85 & 5.4 & 3 & 4.5 & 1.5 & Iris-versicolor & Iris-virginica & 0.965517241 & 0.375 & 0.965517241 & 0.85 \\
\hline 86 & 6 & 3.4 & 4.5 & 1.6 & Iris-versicolor & Iris-virginica & 0.763793103 & 0.178571429 & 0.763793103 & 0.475 \\
\hline
\end{tabular}




\begin{tabular}{|c|c|c|c|c|c|c|c|c|c|c|}
\hline 87 & 6.7 & 3.1 & 4.7 & 1.5 & Iris-versicolor & Iris-virginica & 0.801364943 & 0.232142857 & 0.801364943 & 0.541666667 \\
\hline 135 & 6.1 & 2.6 & 5.6 & 1.4 & Iris-virginica & $\begin{array}{c}\text { Iris- } \\
\text { versicolor }\end{array}$ & 0.4625 & 0.107142857 & 0.41558908 & 0.4625 \\
\hline
\end{tabular}

Table (6): Title of risk

\begin{tabular}{|c|c|l|}
\hline Row & Risk level & Class \\
\hline 1 & Low-risk & $\mathrm{K}_{1}$ \\
\hline 2 & Moderate-risk & $\mathrm{K}_{2}$ \\
\hline 3 & High-risk & $\mathrm{K}_{3}$ \\
\hline 4 & Very High-risk & $\mathrm{K}_{4}$ \\
\hline
\end{tabular}

\section{Case study}

433 In this example, the proposed method is used to assess the seismic risk of 50,000 buildings. The

434 classification of buildings is done in four classes in Table (6), taking into account the simultaneous 435 impact of ten building Characteristics of Table (7).

\begin{tabular}{|c|c|c|c|c|c|}
\hline \multirow[b]{2}{*}{ Index } & \multirow[b]{2}{*}{ Rate } & \multicolumn{4}{|c|}{ Risk level in Characteristics } \\
\hline & & Low & Moderate & High & Very High \\
\hline $\begin{array}{l}\text { Danger of earth } \\
\text { liquefaction (Slope of } \\
\text { the earth in percentage) }\end{array}$ & $X_{1}=[0-45]$ & $\mathrm{E}_{11}=[0-3.86]$ & $\mathrm{E}_{12}=[3.86-12.11]$ & $\mathrm{E}_{13}=[12.11-23.35]$ & $\mathrm{E}_{14}=[23.35-45]$ \\
\hline $\begin{array}{l}\text { Earth movement } \\
\text { (Magnitude of Mercalli } \\
\text { earthquake) }\end{array}$ & $X_{2}=[1-10]$ & $E_{21}=[1-3]$ & $E_{22}=[3-5]$ & $E_{23}=[5-6]$ & $E_{24}=[6-10]$ \\
\hline
\end{tabular}




\begin{tabular}{|c|c|c|c|c|c|}
\hline $\begin{array}{l}\text { Distance of buildings } \\
\text { from explosive stations } \\
\text { (gas and gas stations) } \\
\text { in meters }\end{array}$ & $X_{3}=[0-2000]$ & $E_{31}=[100-2000]$ & $E_{32}=[50-100]$ & $E_{33}=[100-2000]$ & $\mathrm{E}_{34}=[0-20]$ \\
\hline $\begin{array}{l}\text { Type of materials and } \\
\text { structures used in } \\
\text { buildings }\end{array}$ & $\mathrm{X}_{4}=\{1,2, \ldots, 8\}$ & $\mathrm{E}_{41}=\{1,2\}$ & $E_{42}=\{3,4\}$ & $E_{43}=\{5\}$, & $E_{44}=\{7,8\}$ \\
\hline $\begin{array}{l}\text { Type of work of } \\
\text { buildings (per person) }\end{array}$ & $\mathrm{X}_{5}=[0-1000]$ & $E_{51}=[1-25]$ & $E_{52}=[25-75]$ & $E_{53}=[70-100]$ & $E_{54}=[100-1000]$ \\
\hline $\begin{array}{l}\text { Age of buildings (by } \\
\text { year) }\end{array}$ & $\mathrm{X}_{6}=[0-100]$ & $E_{61}=[0-5]$ & $\mathrm{E}_{62}=[5-15]$ & $E_{63}=[15-25]$ & $E_{64}=[25-100]$ \\
\hline $\begin{array}{l}\text { Height of buildings (in } \\
\text { meters) }\end{array}$ & $X_{7}=[1-200]$ & $E_{71}=[1-3]$ & $E_{72}=[3-5]$ & $E_{73}=[5-15]$ & $E_{74}=[15-200]$ \\
\hline Building quality & $\mathrm{X}_{8}=\{1,2,3,4\}$ & $\mathrm{E}_{81}=1$ & $\mathrm{E}_{82}=2$ & $E_{83}=3$ & $\mathrm{E}_{84}=4$ \\
\hline $\begin{array}{l}\text { Density of buildings (in } \\
\text { percentage) }\end{array}$ & $\mathrm{X}_{9}=[0-100]$ & $E_{91}=[0-25]$ & $E_{92}=[25-50]$ & $E_{93}=[50-75]$ & $E_{94}=[75-100]$ \\
\hline $\begin{array}{l}\text { Passage width (in } \\
\text { meters) }\end{array}$ & $X_{10}=[0-100]$ & $\mathrm{E}_{101}=[20-100]$ & $E_{102}=[15-20]$ & $E_{103}=[12-15]$ & $\mathrm{E}_{104}=[1-12]$ \\
\hline
\end{tabular}

439 We display the set of buildings as set $\mathrm{X}$ as follows :

$440 \mathrm{X}=\left\{\left(x_{1}, x_{2}, x_{3}, \ldots, x_{10}\right) \mid x_{i} \in \mathrm{X}_{\mathrm{i}}, \mathrm{i}=1, \ldots, 10\right\}, \mathrm{X}_{\mathrm{i}}$ sets are defined in Table (7).

441

Table (8): Characteristics frequency table

\begin{tabular}{|c|c|c|c|c|}
\hline characteristics & Min & Max & average & standard deviation \\
\hline$x_{1}$ & 1 & 44.998 & 3.7758 & 12.6818 \\
\hline$x_{2}$ & 1 & 10 & 2.3182 & 2.8091 \\
\hline$x_{3}$ & 0 & 2000 & 19.6833 & 514.5335 \\
\hline$x_{4}$ & 1 & 8 & 2.1224 & 2.2875 \\
\hline$x_{5}$ & 1 & 1000 & 16.2825 & 406.8242 \\
\hline$x_{6}$ & 0 & 100 & 5.9288 & 31.8835 \\
\hline
\end{tabular}




\begin{tabular}{|c|c|c|c|c|}
\hline$x_{7}$ & 2 & 200 & 7.2686 & 53.8127 \\
\hline$x_{8}$ & 1 & 4 & 1.5818 & 1.1188 \\
\hline$x_{9}$ & 0 & 100 & 5.9418 & 31.8808 \\
\hline$x_{10}$ & 1 & 100 & 5.9477 & 31.7565 \\
\hline
\end{tabular}

443

444

445 The boundaries of the classes for each of the ten properties are specified in Table (7) (risk level in

446 characteristics columns). As mentioned earlier, defining the class structure in Table (6) for

447 buildings (set $\mathrm{X}$ ) is one of the main challenges. For this purpose, based on the proposed method,

448 we define a granular structure based on fuzzy hypergraphs.

449 In the first step, based on the Definition 3.1 elements of the matrix E, which are the classes of each

450 property, $X_{i}$ is defined based on the concept of the classes in Table (6). As shown in Table (7),

451 these classes are listed in four columns: Low, Moderate, High, Very High.

452 To provide the best data, the frequency tables of properties (see Table (8)) and the percentage of

453 class properties (Table (9)) and the composition chart (see Figure (7)) of the class properties are

454 given.

Table (9): Percentage of characteristics belonging to classes table

\begin{tabular}{|c|c|c|c|c|}
\hline $\begin{array}{c}\text { Characteristics } \\
\text { Symbol }\end{array}$ & low-risk & moderate-risk & high-risk & very high-risk \\
\hline$x_{1}$ & $\% 18.996$ & $\% 43.714$ & $\% 12.704$ & $\% 24.586$ \\
\hline$x_{2}$ & $\% 20.434$ & $\% 20.798$ & $\% 10.2$ & $\% 48.568$ \\
\hline$x_{3}$ & $\% 46.37$ & $\% 14.552$ & $\% 8.486$ & $\% 30.592$ \\
\hline$x_{4}$ & $\% 24.846$ & $\% 25.108$ & $\% 25.116$ & $\% 24.93$ \\
\hline$x_{5}$ & $\% 31.882$ & $\% 15.174$ & $\% 7.558$ & $\% 45.386$ \\
\hline$x_{6}$ & $\% 18.034$ & $\% 24.956$ & $\% 6.452$ & $\% 50.558$ \\
\hline
\end{tabular}




\begin{tabular}{|c|c|c|c|c|}
\hline$x_{7}$ & $\% 4.31$ & $\% 8.978$ & $\% 26.526$ & $\% 60.186$ \\
\hline$x_{8}$ & $\% 25.08$ & $\% 24.628$ & $\% 25.288$ & $\% 25.004$ \\
\hline$x_{9}$ & $\% 49.276$ & $\% 16.82$ & $\% 16.534$ & $\% 17.37$ \\
\hline$x_{10}$ & $\% 53.928$ & $\% 3.328$ & $\% 2.112$ & $\% 40.632$ \\
\hline
\end{tabular}

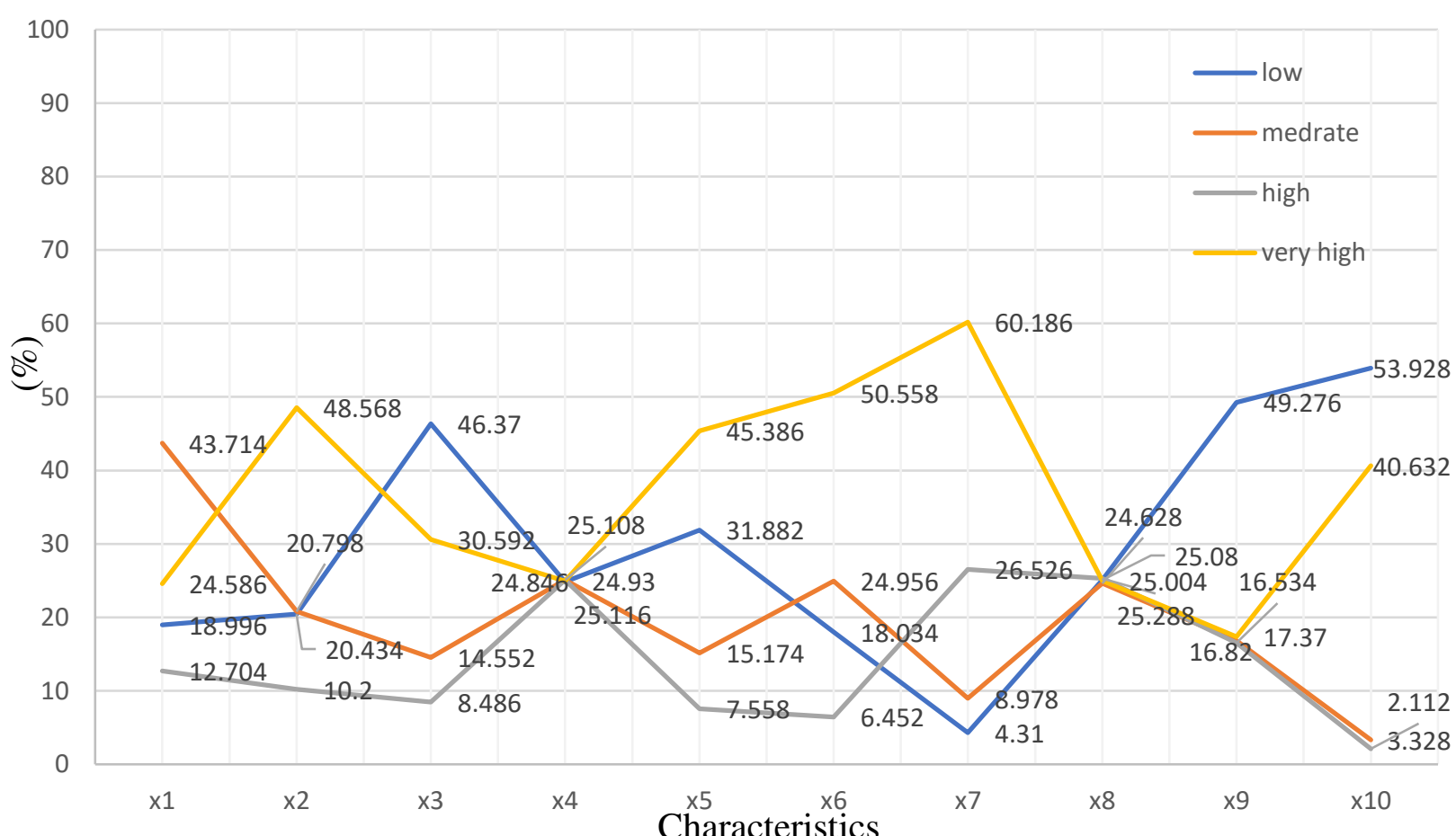

Figure (7): Percentage of characteristics belonging to classes chart

459 Now we define the fuzzy membership functions on the $\mathrm{E}_{i j}$ interval. In this example, Gaussian

460 functions are used to determine the degree of membership of properties to each of the four classes

461 defined on the characteristics set. Functions are defined as follows:

462 It is clear $\mathrm{E}_{i j} \subset \mathrm{X}_{i}, \mathrm{E}_{i j}^{c}=\mathrm{X}_{i}-\mathrm{E}_{i j}$ for $\mathrm{i}=1,2, \ldots, 10, \mathrm{j}=1,2,3,4$.

$463 \quad \mu_{\mathrm{i} 1}: \mathrm{E}_{\mathrm{i} 1} \rightarrow[0,1]$ such that $\mu_{\mathrm{i} 1}(x)=e^{\frac{\ln (0.001) \times\left(x-a_{i 1}\right)^{2}}{c_{i 1}^{2}}}$ where $\mathrm{E}_{\mathrm{i} 1}=\left[a_{\mathrm{i} 1}, c_{\mathrm{i} 1}\right], \mathrm{i}=1,2,3, \ldots, 10$ 
$464 \quad \mu_{\mathrm{i} 1}^{\mathrm{c}}: \mathrm{E}_{\mathrm{i} 1}^{\mathrm{c}} \rightarrow[0,1]$ such that $\mu_{\mathrm{i} 1}^{\mathrm{c}}(x)=e^{\frac{\ln (0.001) \times\left(x-b_{i 1}\right)^{2}}{b_{i 1}^{2}}}$ where $\mathrm{E}_{\mathrm{i} 1}^{\mathrm{c}}=\left(\mathrm{c}_{\mathrm{i} 1}, \mathrm{~b}_{\mathrm{i} 1}\right], \mathrm{i}=1,2,3, \ldots, 10$

$465 \quad \mu_{\mathrm{i} 2}: \mathrm{E}_{\mathrm{i} 2} \rightarrow[0,1]$ such that $\mu_{\mathrm{i} 2}(x)=e^{\frac{\ln (0.001) \times\left(x-\frac{c_{i 2}+d_{i 2}}{2}\right)^{2}}{\left(\frac{c_{i 2}+d_{i 2}}{2}\right)^{2}}}$ where $\mathrm{E}_{\mathrm{i} 2}=\left[c_{\mathrm{i} 2}, d_{\mathrm{i} 2}\right], \mathrm{i}=1,2,3, \ldots, 10$

$466 \quad \mu_{\mathrm{i} 2}^{\mathrm{c}}: \mathrm{E}_{\mathrm{i} 2}^{\mathrm{c}} \rightarrow[0,1] \quad$ such that $\mu_{\mathrm{i} 2}^{\mathrm{c}}(x)= \begin{cases}e^{\frac{\ln (0.001) \times\left(x+\left(b_{i 2}-\frac{\left(c_{i 2}+d_{i 2}\right)}{2}\right)\right)^{2}}{b_{i 2}{ }^{2}}} & \text { where } x \in\left[\mathrm{a}_{\mathrm{i} 2}, \mathrm{c}_{\mathrm{i} 2}\right) \\ e^{\frac{\ln (0.001) \times\left(x-\left(b_{i 2}-\frac{\left(c_{i 2}+d_{i 2}\right)}{2}\right)\right)^{2}}{b_{i 2}{ }^{2}}} & \text { where } x \in\left(\mathrm{d}_{\mathrm{i} 2}, \mathrm{~b}_{\mathrm{i} 2}\right]\end{cases}$

$467 \quad \mu_{\mathrm{i} 3}: \mathrm{E}_{\mathrm{i} 3} \rightarrow[0,1]$ such that $\mu_{\mathrm{i} 3}(x)=e^{\frac{\ln (0.001) \times\left(x-\frac{d_{i 3}+e_{i 3}}{2}\right)^{2}}{\left(\frac{d_{i 3}+e_{i 3}}{2}\right)^{2}}}$ where $\mathrm{E}_{\mathrm{i} 3}=\left[\mathrm{d}_{\mathrm{i} 3}, e_{\mathrm{i} 3}\right], \mathrm{i}=1,2,3, \ldots, 10$

$468 \quad \mu_{\mathrm{i} 3}^{\mathrm{c}}: \mathrm{E}_{\mathrm{i} 3}^{\mathrm{c}} \rightarrow[0,1] \quad$ such that $\mu_{\mathrm{i} 3}^{\mathrm{c}}(x)= \begin{cases}e^{\frac{\ln (0.001) \times\left(x+\left(b_{i 3}-\frac{e_{i 3}+d_{i 3}}{2}\right)\right)^{2}}{b_{\mathrm{i} 3}^{2}}} & \text { where } x \in\left[\mathrm{a}_{\mathrm{i} 3}, \mathrm{~d}_{\mathrm{i} 3}\right) \quad \mathrm{i}=1,2,3, \ldots, 10 \\ e^{\frac{\ln (0.001) \times\left(x-\left(b_{i 3}-\frac{e_{i 3}+d_{i 3}}{2}\right)\right)^{2}}{b_{\mathrm{i} 3}^{2}}} & \text { where } x \in\left(\mathrm{e}_{\mathrm{i} 3}, \mathrm{~b}_{\mathrm{i} 3}\right]\end{cases}$

$469 \quad \mu_{\mathrm{i} 4}: \mathrm{E}_{\mathrm{i} 4} \rightarrow[0,1]$ such that $\mu_{\mathrm{i} 4}(x)=e^{\frac{\ln (0.001) \times\left(x-b_{i 4}\right)^{2}}{\left(b_{i 4}-e_{i 4}\right)^{2}}}$ where $\mathrm{E}_{\mathrm{i} 4}=\left[e_{\mathrm{i} 4}, \mathrm{~b}_{\mathrm{i} 4}\right], \mathrm{i}=1,2,3, \ldots, 10$

$470 \quad \mu_{\mathrm{i} 4}^{\mathrm{c}}: \mathrm{E}_{\mathrm{i} 4}^{\mathrm{c}} \rightarrow[0,1]$ such that $\mu_{\mathrm{i} 4}^{\mathrm{c}}(x)=e^{\frac{\ln (0.001) \times\left(x-a_{i 4}\right)^{2}}{e_{i 4}^{2}}}$ where $\mathrm{E}_{\mathrm{i} 4}^{\mathrm{c}}=\left[\mathrm{a}_{\mathrm{i} 4}, \mathrm{e}_{\mathrm{i} 4}\right), \mathrm{i}=1,2,3, \ldots, 10$

471 In the following, the membership of $x_{10}=(5,4,669,2,60,43,103,3,11,49)$ element in the four risk

472 categories is examined. We form matrix $\theta_{x}$ (Definition 3.4) based on the above membership

473 functions. By forming matrix $\theta_{x}$, the score values are calculated based on the Definition 3.5. 


$$
\theta_{x}=\left(\begin{array}{cccc}
-0.0043 & 0.3809 & -0.02870 & -0.9183 \\
-0.0832 & 1 & -0.0068 & -0.537 \\
0.0469 & -0.0329 & -0.0399 & -0.0441 \\
1 & -0.1667 & -0.5 & -0.8333 \\
-0.0022 & 0.7586 & -0.0015 & -0.9762 \\
-0.106 & -0.045 & -0.0166 & 0.0185 \\
-0.1969 & -0.1718 & -0.1359 & 0.1497 \\
-0.6667 & -0.3333 & 1 & -0.3333 \\
0.2625 & -0.024 & -0.1969 & -0.9198 \\
0.1658 & -0.0391 & -0.0565 & -0.0983
\end{array}\right)
$$

475 From Definition 3.5:

476

$$
\begin{aligned}
& \text { score }_{1}(x)=0.4159 \\
& \text { score }_{2}(x)=1.3267 \\
& \text { score }_{3}(x)=0.0172 \\
& \text { score }_{4}(x)=-4.5179
\end{aligned}
$$

477 By Definition 3.7 and functions $\mu, \eta$ the values $\operatorname{DoNM}_{\text {score }_{\mathrm{j}}}, \operatorname{DoM}_{\text {score }_{\mathrm{j}}}$ are calculated for

$478 \mathrm{i}=1,2,3,4$.

479

$\mu:[0, \mathrm{n}] \rightarrow[0,1]$ such tath $\mu(x)=e^{\frac{-6.90 *(x-10)^{2}}{100}}$

480

and

481

$$
\eta:[-n, 0] \rightarrow[0,1] \text { such tath } \eta(x)=e^{\frac{-6.90^{*}(x+10)^{2}}{100}}
$$




$$
\begin{aligned}
& \operatorname{DoM}_{\text {score }_{1}}(x)=\mu\left(\operatorname{score}_{1}(x)\right)=\mu(0.4159)=0.0018 \\
& \operatorname{DoM}_{\text {score }_{2}}(x)=\mu\left(\operatorname{score}_{2}(x)\right)=\mu(1.3267)=0.0056 \\
& \operatorname{DoM}_{\text {score }_{3}}(x)=\mu\left(\operatorname{score}_{3}(x)\right)=\mu(0.0172)=0.001 \\
& \operatorname{DoNM}_{\text {score }_{4}}(x)=\eta\left(\operatorname{score}_{4}(x)\right)=\eta(-4.5179)=0.1253 .
\end{aligned}
$$

Because there exists the largest membership degree therefore, by Definition 3.8 we consider element $x_{10}=(5,4,669,2,60,43,103,3,11,49)$ to belong to the moderate-risk class with a

487 membership grade of 0.0056 .

488 Due to the high dispersion of the properties of this element, the membership grade is not strong in any of the grade classes, but this method has the ability to classify with the least similarity. This is how other buildings are classified. Table (10) shows the percentage of 50,000 buildings 491 belonging to the four classes.

Table (10): Percentage of affiliation

\begin{tabular}{|c|c|c|c|c|}
\hline Low-risk & Moderate-risk & High-risk & Very-high & No classification \\
\hline$\% 15.154$ & $\% 10.882$ & $\% 26.936$ & $\% 35.468$ & $\% 11.56$ \\
\hline
\end{tabular}

\section{Conclusions}

In this paper, a method for assessing the vulnerability of urban areas was presented using granular

497 calculations and the concepts of fuzzy hypergraphs. In the proposed model, it was shown that fuzzy 498 hypergraphs, compared to other methods, have the ability to define a flexible granular structure 499 for different urban hazard classes. As an innovation of the proposed method, we can mention its 
500 flexibility in classifying elements, considering the role of all effective parameters, both equal 501 weight and heterogeneity in classification.

502 In verifying the proposed method, it has been shown that the classification of iris flowers with the 503 proposed method is more than $90 \%$ consistent with the intuitive classification of Fisher. The low 504 degree of membership of some flowers in all three classes indicates an excessive dispersion of 505 characteristics.

506 Using the proposed method in assessing the seismic vulnerability of 50,000 buildings, it is possible 507 to simultaneously play the role of 10 heterogeneous and sometimes equal weight properties in the 508 classification.

509 Examination of the obtained results indicates the flexibility and accuracy of the proposed method 510 in classifying elements with any number of heterogeneous and equal parameters. This study shows 511 that fuzzy hypergraphs have the ability to define a flexible granular structure, taking into account 512 the simultaneous role of all effective parameters in classification.

\section{Declarations}

515 - Availability of data and materials

516 The datasets used and/or analyzed during the current study are available from the 517 corresponding author on reasonable request.

$518 \cdot$ Competing interests

519 The authors declare that they have no competing interests.

$520 \cdot$ Funding

521 There are no sources of funding for the research reported.

522 - Authors' contributions 
523 Zarandi Baghini performed a new method of granular computing and developed the fuzzy 524 hypergraphs and also analyzed and interpreted the computer proceeding data regarding the urban vulnerability and the verification of the previous experimental study. Tabatabaei Mirhosseini performed the background to the study, and was a major contributor in writing the manuscript. Babaei read and approved the final manuscript.

- Acknowledgements

Not applicable

\section{References}

532 1. Ferreira MA, De Sá FM, Oliveira CS. Disruption Index, DI: an approach for assessing

533 seismic risk in urban systems (theoretical aspects). Bulletin of earthquake engineering. $534 \quad 2014 ; 12(4): 1431-58$.

535 2. Davidson R. EERI annual student paper award a multidisciplinary urban earthquake 536 disaster risk index. Earthquake Spectra. 1997;13(2):211-23.

537 3. Dueñas-Osorio L, Craig JI, Goodno BJ. Seismic response of critical interdependent networks. Earthquake engineering \& structural dynamics. 2007;36(2):285-306.

539 4. Hubbard DW. The failure of risk management: Why it's broken and how to fix it. John $540 \quad$ Wiley \& Sons; 2020.

541 5. Cardona O. Indicators of disaster risk and risk management: Summary report. Inter542 American Development Bank; 2005.

543 6. Bilham R. The seismic future of cities. Bulletin of earthquake engineering. 2009;7(4):839-87.

545 7. Carreño ML, Cardona OD, Barbat AH. New methodology for urban seismic risk assessment from a holistic perspective. Bulletin of earthquake engineering. 2012;10(2):547-65.

548 8. Michaud D, Apostolakis GE. Methodology for ranking the elements of water-supply 
networks. Journal of infrastructure systems. 2006;12(4):230-42.

550 9. Masure P, Lutoff C. Urban system exposure to natural disasters: an integrated approach. In: Assessing and Managing Earthquake Risk. Springer; 2008. p. 239-60.

552 10. Nazionale SS. Gruppo Nazionale per la Difesa dai Terremoti. Scheda AeDES di. 2000;1.

553 11. Whitman R V. Damage probability matrices for prototype buildings. Structures $554 \quad$ Publication. 1973;380.

555 12. Corsanego A, Petrini V. Evaluation of criteria of seismic vulnerability of the existing 556 building patrimony on the national territory. Seismic Engineering. 1994;1:76-106.

557 13. Bernardini A. The vulnerability of buildings-Evaluation on the national scale of the 558 seismic vulnerability of ordinary buildings. CNR-GNDT, Rome. 2000;

559 14. Lantada N, Pujades LG, Barbat AH. Vulnerability index and capacity spectrum based 560 methods for urban seismic risk evaluation. A comparison. Natural Hazards. 2009;51(3):501.

562 15. Shvartzshnaider Y, Ott M. Design for change: Information-centric architecture to support agile disaster response. In: 2013 IEEE International Conference on Communications (ICC). IEEE; 2013. p. 4025-9.

565 16. Jain AK. Data clustering: 50 years beyond K-means. Pattern recognition letters. $566 \quad 2010 ; 31(8): 651-66$.

567 17. De Angelis L, Dias JG. Mining categorical sequences from data using a hybrid clustering 568 method. European Journal of Operational Research. 2014;234(3):720-30.

569 18. Pedrycz W. Granular computing: analysis and design of intelligent systems. CRC press; 570 2018.

571 19. Yao YYY, Liau C-J, Zhong N. Granular computing based on rough sets, quotient space 
theory, and belief functions. In: International Symposium on Methodologies for Intelligent Systems. Springer; 2003. p. 152-9.

574 20. Yao YY, Zhong N. Granular computing using information tables. Data mining, rough sets 575 and granular computing. 2002;102-24.

576 21. Pedrycz W. Fuzzy modelling: paradigms and practice. Vol. 7. Springer Science \& $577 \quad$ Business Media; 2012.

578 22. Chiaselotti G, Ciucci D, Gentile T, Infusino F. Rough set theory applied to simple undirected graphs. In: International Conference on Rough Sets and Knowledge 580 Technology. Springer; 2015. p. 423-34.

581 23. Bretto A. Hypergraph theory. An introduction Mathematical Engineering Cham: Springer. $582 \quad 2013$

583 24. Karypis G, Kumar V. Multilevel k-way hypergraph partitioning. VLSI design. $584 \quad 2000 ; 11(3): 285-300$.

585 25. Zadeh LA. Toward a theory of fuzzy information granulation and its centrality in human reasoning and fuzzy logic. Fuzzy sets and systems. 1997;90(2):111-27.

587 26. Wang Q, Gong Z. An application of fuzzy hypergraphs and hypergraphs in granular 588 computing. Information Sciences. 2018;429:296-314.

589 27. Kauffman A. Introduction a la Theorie des Sous-emsembles Flous, Masson et Cie. vol; 590 1973.

591 28. Zadeh LA. Similarity relations and fuzzy orderings. Information sciences. 1971;3(2):177$592 \quad 200$.

593 29. Mordeson JN, Nair PS. Cycles and cocycles of fuzzy graphs. Information Sciences. 594 1996;90(1-4):39-49. 
595 30. Mordeson JN, Nair PS. Fuzzy graphs and fuzzy hypergraphs. Vol. 46. Physica; 2012.

596 31. Rosenfeld A. Fuzzy graphs, Fuzzy Sets and their Applications (LA Zadeh, KS Fu, M.

597 Shimura, Eds.). Academic Press, New York; 1975.

598 32. Bhattacharya P. Some remarks on fuzzy graphs. Pattern recognition letters.

$599 \quad 1987 ; 6(5): 297-302$.

600 33. Sunitha MS, Vijayakumar A. A characterization of fuzzy trees. 1999;

601 34. Sunitha MS, Vijayakumar A. Studies on fuzzy graphs. Department of Mathematics; 2001.

602 35. Bhutani KR, Battou A. On M-strong fuzzy graphs. Information Sciences. 2003;155(1-

6032 2):103-9.

604 36. Bustince Sola H, Burillo López P. A theorem for constructing interval-valued

605 intuitionistic fuzzy sets from intuitionistic fuzzy sets. Notes on Intuitionistic Fuzzy Sets 1

$606 \quad$ (1995) 5-16. 1995;

607 37. Goetschel Jr RH. Introduction to fuzzy hypergraphs and Hebbian structures. Fuzzy Sets $608 \quad$ and Systems. 1995;76(1):113-30.

609 38. Lee-Kwang H, Lee K-M. Fuzzy hypergraph and fuzzy partition. IEEE transactions on

610 systems, man, and cybernetics. 1995;25(1):196-201.

611 39. Parvathi R, Thilagavathi S, Karunambigai MG. Intuitionistic fuzzy hypergraphs.

612 Cybernetics and Information Technologies. 2009;9(2):46-53.

613 40. Lee K-M, LEE K-M, CIOS KJ. Comparison of interval-valued fuzzy sets, intuitionistic

614 fuzzy sets, and bipolar-valued fuzzy sets. In: Computing and Information Technologies:

615 Exploring Emerging Technologies. World Scientific; 2001. p. 433-9.

616 41. Zadeh LA. Information and control. Fuzzy sets. 1965;8(3):338-53.

617 42. Stell JG. Relational granularity for hypergraphs. In: International Conference on Rough 
Sets and Current Trends in Computing. Springer; 2010. p. 267-76.

619 43. Fisher RA. The use of multiple measurements in taxonomic problems. Annals of eugenics.

620 1936;7(2):179-88.

621 44. Zadeh LA, Klir GJ, Yuan B. Fuzzy sets, fuzzy logic, and fuzzy systems: selected papers.

622 Vol. 6. World Scientific; 1996.

623 45. Berge C. Graphs and hypergraphs. 1973;

624 